\title{
The Experimental Analysis of Vibration Monitoring in System Rotor Dynamic with Validate Results Using Simulation Data
}

\author{
Hisham A. H. Al-Khazali ${ }^{1}$ and Mohamad R. Askari ${ }^{2}$ \\ ${ }^{1}$ Faculty of Science, Engineering and Computing, School of Mechanical and Automotive Engineering, Kingston University, \\ London SW15 3DW, UK \\ ${ }^{2}$ Faculty of Science, Engineering and Computing, School of Aerospace and Aircraft Engineering, Kingston University, \\ London SW15 3DW, UK \\ Correspondence should be addressed to Hisham A. H. Al-Khazali, k0903888@kingston.ac.uk
}

Received 12 December 2011; Accepted 19 January 2012

Academic Editor: D. Zhou

Copyright (c) 2012 H. A. H. Al-Khazali and M. R. Askari. This is an open access article distributed under the Creative Commons Attribution License, which permits unrestricted use, distribution, and reproduction in any medium, provided the original work is properly cited.

\begin{abstract}
There is a growing tendency today to extract information about the prognostic parameters based on system analysis through various diagnostic techniques to assess the health of the plant or equipment. Vibration monitoring helps in reducing the machine down time. A vibration signature measured at the external surface of machine or at any other suitable place contains a good amount of information to reveal the running condition of the machine. Considering the importance of vibration monitoring in the rotating machinery fault diagnostics, it has been applied in this paper. Effects of modal parameters like natural frequency, mode shapes, and damping, misalignments have been studied. Balancing is usually an expensive and laborious procedure and a balancing system would be beneficial for motor engine and power generation application. In this research, there have been identified unbalance parameters that exist in rotating machinery and develop a finite-element model of rotating dynamics system to create a mathematical model of the system from the test data and subsequently obtaining the unbalanced parameters. During this study, the raw data obtained from the experimental results (Smart Office software) are curve fitted by theoretical data regenerated from simulating it using finite element (ANSYS 12) model for comparisons. The experimental analysis used thus far is called Modal Testing, a well-known and widely used technique in research and industry to obtain the Modal and Dynamic response properties of structures. The technique has recently been applied to rotating structures and some research papers been published, however, the full implementation of Modal Testing in active structures and the implications are not fully understood and are therefore in need of much further and more in-depth investigations. The aim is to find a system identification methodology using the analytical/computational techniques and update the model using experimental techniques already established for passive structures but to active rotating structures, which subsequently help to carry out health monitoring as well as further design and development in rotating machinery.
\end{abstract}

\section{Introduction}

As the rotating machine wears, foundations settle, and parts deform, subtle changes in the dynamic properties of the machine begin to occur. Shafts become misaligned, parts begin to wear, rotors become unbalanced, and clearances increase. All of these factors are reflected in an increase in vibration energy, which as it is dissipated throughout the machine, excites resonances, and puts considerable extra dynamic loads on bearings. Increased complexities of rotating machinery and demands for higher speeds and greater power have created complex vibration problems. Engineering judgments based on understanding of physical phenomena are needed to provide the diagnosis and methods for correcting the rotating machinery faults $[1,2]$. Modes are used as a simple and efficient means of characterizing resonant vibration. The majority of structures can be made to resonate. That is, under the proper conditions, a structure can be made to vibrate with excessive, sustained, and oscillatory motion. Resonant vibration is caused by an interaction between the inertial and elastic properties of the materials within a structure. Resonant vibration is often 
the cause of, or at least a contributing factor to, many of the vibration related problems that occur in structures and operating machinery. To better understand any structural vibration problem, the resonances of a structure need to be identified and quantified. A common way of doing this is to define the structure's modal parameters [1-3].

Modes (or resonances) are inherent properties of a structure. Resonances are determined by the material properties (mass, stiffness, and damping properties), and boundary conditions of the structure. Each mode is defined by a natural (modular resonant) frequency, modal damping, and a mode shape. If either the material properties or the boundary conditions of a structure change, its modes will change. For instance, if mass is added to a vertical pump, it will vibrate differently because its modes have changed. At or near the natural frequency of a mode, the overall vibration shape (operating deflection shape) of a machine or structure will tend to be dominated by the mode shape of the resonance.

Rotor dynamics is the study of vibration behavior in axially symmetric rotating structures. Devices such as engines, motors, disc drives, and turbines all develop characteristic inertia effects that can be analyzed to improve the design and decrease the possibility of failure. At higher rotational speeds, such as in a gas turbine engine, the inertia effects of the rotating parts must be consistently represented in order to accurately predict the rotor behavior $[2,3]$.

1.1. Existing Technique Used for Modelling. There has been a long-standing interest in rotor dynamic modelling that has evolved since the first and incorrect rotor dynamic analysis by Rankine in 1869 . They need to understand the system response to design predictable, low maintenance, costeffective, and optimal systems that have driven rotor dynamics to often model large-order complex rotor system models. The models contain more intricate geometric complexities, bearings, seals, and attached components such as discs, blades, fans, and couplings. Some models involve relatively simple beam representations of the rotor on bearings that are represented as stiffness and damping. These models do not usually need reduction so they are not the topic covered here. The standard analysis of rotor systems includes critical speeds, stability and unbalanced response [4].

In recent years with continuing demands for increased performance, many rotating industrial machines are now being designed for operation at high speed, a trend which has resulted in increased mechanical vibration and noise problems [2]. The modal model (natural frequencies, mode shapes, and modal damping) of a complete machine based on the in-situ experimental modal tests is one possible modelling approach. Irretier [5] gave an overview of the different experimental modal analysis techniques. Such an experimental model is expected to avoid all uncertainties in the mathematical modelling approach (often FE Model) and its updating. However, conducting modal tests on a machine such as a TG set, which has a number of fluid bearings, is not straightforward. The dynamics of the fluid bearings during machine operation and the rotation of the shaft itself influence the dynamic behaviour of the complete machine, which imposes certain limitations on the modal testing for rotating machines. Bucher and Ewins [6] have discussed these issues in detail. Irretier [7] gave the mathematical background to extract the modal model for rotating structures which are characterised by nonsymmetric and time-variant matrices, unlike the assumptions for the experimental modal analysis of stationary structures, namely, a linear, time-invariant system where reciprocity holds. Another alternative is the use of a modal model of the foundation alone together with the FE model of the rotor and the mathematical model for the bearings, Pennacchi et al. [8].

In this paper, searching for a new technique to interpret the results obtained from experimental data of dynamic performance of machinery for condition monitoring, it is clear that a database could be created. This database consists of complete mathematical model of the machine which includes both the supporting structures as well as the moving parts and is based on the structural dynamics characteristics of the system $[9,10]$.

Linear structures for the purpose of vibration analysis may be modelled either as a continuous system or a discrete one. In the case of the latter method, the mass of the system is lumped into a finite number of masses connected by springs and dampers representing the stiffness and damping in the system, respectively. The system is then said to possess a finite number of degrees of freedom. Damping mechanism comes in different forms such as viscous, structural, hysteretic, and coulomb. The viscous damping being the most common form. The equations of motion of the discrete model consists of a finite number of second-order ordinary differential equations coupled together, in which case they have to be solved simultaneously $[2,9,11]$. The process becomes progressively more difficult as the number of degrees of freedom increases.

1.2. Measurement of Frequency Response Functions (FRFs). A natural frequency may be detected experimentally by exciting the structure with transient or a harmonic force each method has a different application depending on the objective of the test and the time available. For example, impact testing with a hammer, which is quick and easy, is ideal for studying a car's exhaust system's vibration problem and varying the frequency until "resonance" is achieved. At resonance, the mode associated with the natural frequency may be observed [1]. The frequency response function (FRF) is a fundamental measurement that isolates the inherent dynamic properties of a mechanical structure. Experimental modal parameters (frequency, damping, and mode shape) are also obtained from a set of FRF measurements. The FRF describes the input-output relationship between two points on a structure as a function of frequency. Therefore, an FRF is actually defined between a single input DOF (point and direction), and a single output (DOF), although the FRF was previously defined as a ratio of the Fourier transforms of an output and input signal, is it actually computed differently in all modern (FFT) analyzers. This is done to remove random noise and nonlinearity (distortion) from the (FRF) estimates. 
Rotating machines such as steam or gas turbines, turbogenerators, internal combustion engines, motors, and disc drives can develop inertia effects that can be analyzed to improve the design and decrease the possibility of failure $[1,12]$. Current trends in rotating equipment design focus on increased speeds, which increase operational problems caused by vibration. At higher rotational speeds, the inertia effects of rotating parts must be consistently represented to accurately predict rotor behaviour $[3,6]$.

\section{Objective}

The target of this paper is to utilize the developed solution module in investigating assorted aspects of the vibration performance of an induction motor system for solving its failure trouble of the shaft. Some of the crucial factors to the quality and performance of the motor, such as the vibration amplitude as resulted from the bearing wear, damping effects, and the passing of system resonance critical speeds, are all investigated in the study. An efficient dual-rotor model is verified to have excellent accuracy when comparing the calculated frequency response function (FRF) with that from modal testing. Present paper is to investigate the effects of design parameters on the noise produced by rotor-bearing systems.

Mathematical model of the system from the test data can be assembled. Transient orbit analysis in the literature indicates that the bearing stiffness and damping dominates the vibration amplitude remarkably. In this project, the damping effects of the stiffness of bearings have been studied. The research work included the development of relevant theoretical groundwork originated from principles of rotor dynamics. The method would be capable of solving many of the related rotating machine problems such as high-speed gas-bearing spindle and electric motors.

Excess vibration can cause noise and wear in machinery and bearing, it is important to identify all the critical speeds within the range of operation and analyse the damping effects, mass unbalance and other phenomena in rotating machinery and their effects in the safe operation of rotating machinery, which would be the subject of study in this paper which will help to obtain the necessary results for reducing amplitude and subsequently reducing noise happened due to excess vibration in bearing through the reaction forces act in right and left bearing with increasing the speed of rotation. It is envisaged that the approach is not limited to the condition monitoring and predictive failure but could help the designers to have better understanding of rotor performance at the system design stage.

\section{Method}

\subsection{Mathematical Model}

3.1.1. Description of Frequency Response Functions (FRFs). The derivative processes of FRFs are described here. The FRF data of any structure can also be obtained through experimental modal testing or by means of the FE simulation

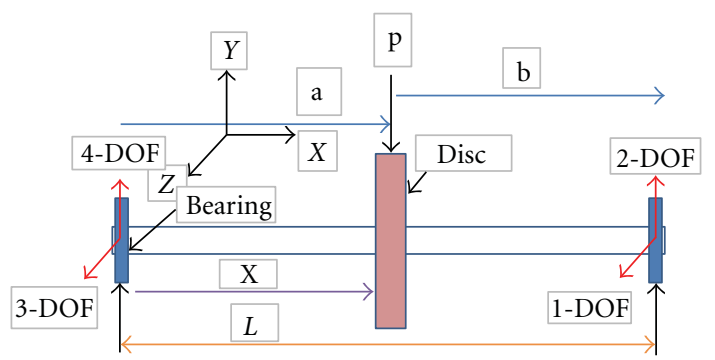

Figure 1: Schematic of a rotor one disc setup parameter [2, 3].

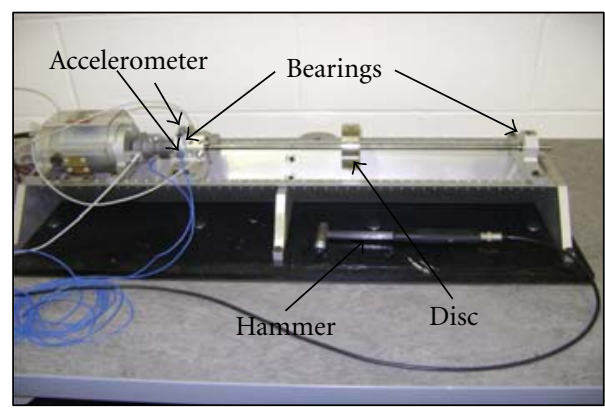

Figure 2: Experimental setup for the modal testing.
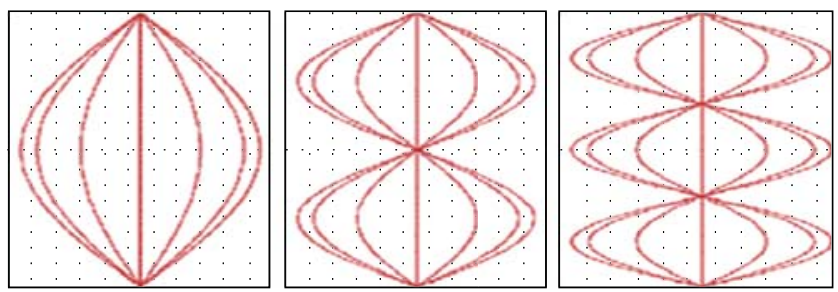

1st flexural mode shape, 2nd flexural mode shape, 3rd flexural mode shape

Figure 3: Basic machine model cross-section [2, 3].

method [2]. For the vibration equation of a system, the mathematical model can be expressed as follows [9]:

$$
M \ddot{x}+C \dot{x}+K x=f,
$$

where $M, C$, and $K$ are the mass, damping, and stiffness matrices of the system, respectively. Moreover, $x$ and $f$ are the displacement and external force vectors, respectively. In (1), the displacement vector of the system can be represented in the modal coordinate with the following mode shape matrix:

$$
x_{N \times 1}=\sum_{r=1}^{N} \eta_{r} \nu_{r}=U_{N \times N} \eta_{N \times 1},
$$

where $N$ is the total number of components in the modal coordinate; $\eta_{r}$ and $\nu_{r}$ are the components of the modal coordinate and the mode shape vector at the $r$ th mode, respectively; $U=v_{1}, v_{2}, \ldots, \nu_{N}$ denotes the mode shape matrix; $\eta=\eta_{1}, \eta_{2}, \ldots, \eta_{N}{ }^{T}$ refers to the modal coordinate 

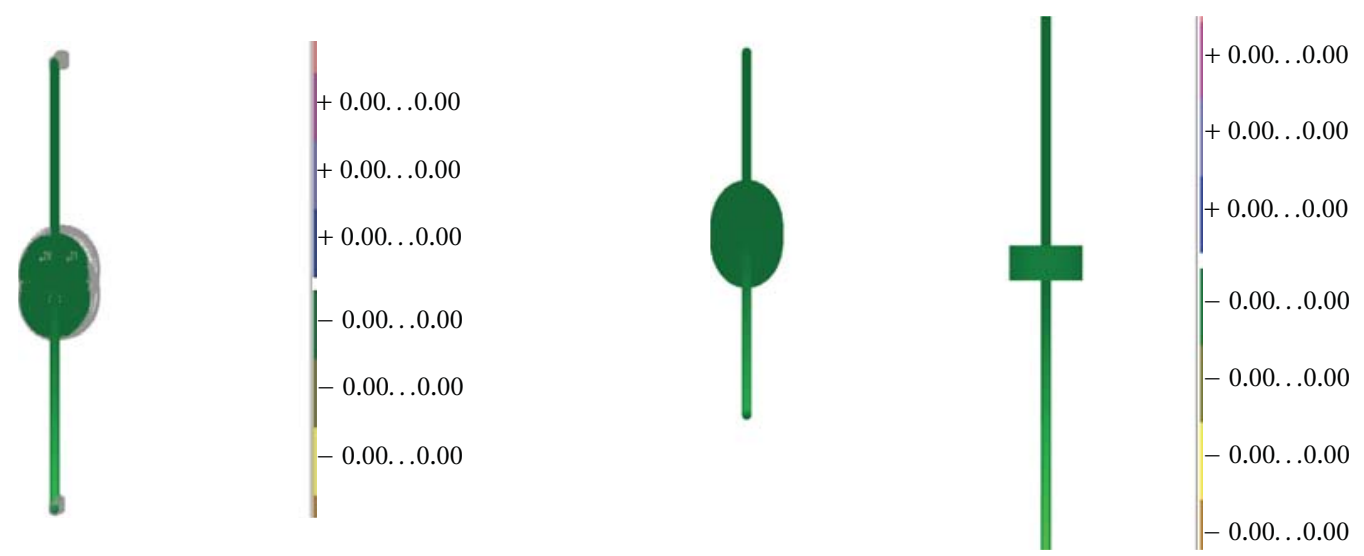

(a) At start rotation

Geometry3

$29.79 \mathrm{~Hz}$ reference accelorometer $(\mathrm{m} / \mathrm{N})$
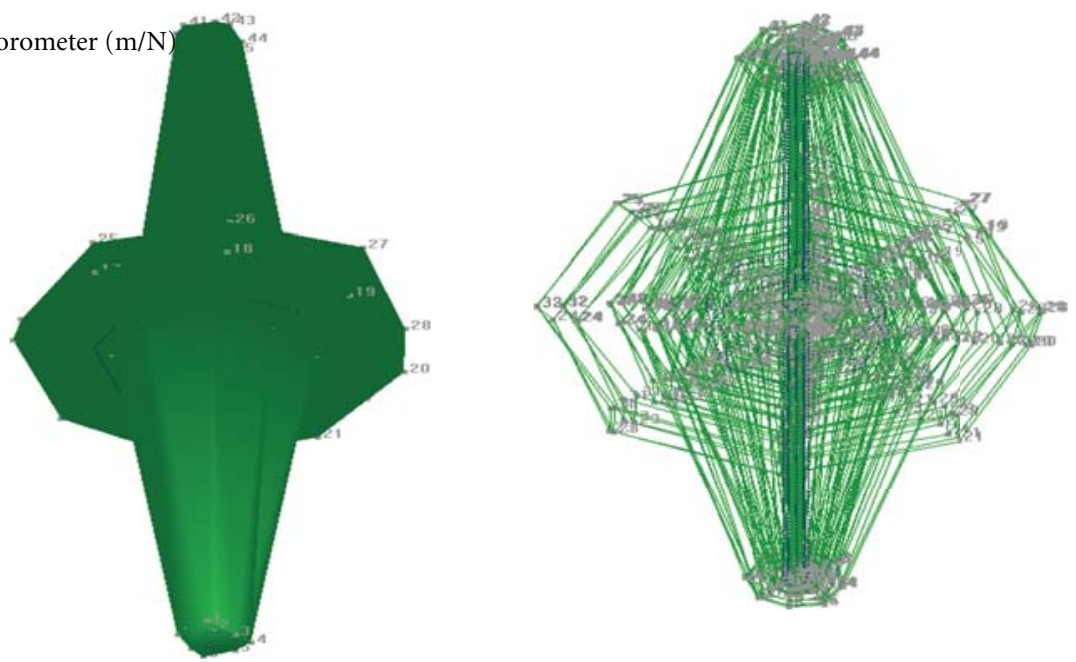

(b) After rotation (first mode shape)

FIgURE 4: Geometry design for model (one disc in the middle), experimental test using Smart Office.

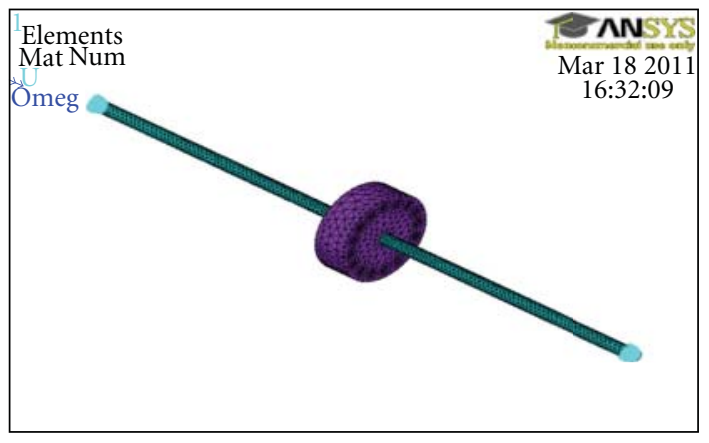

(a) ANSYS (APDL), (3D)

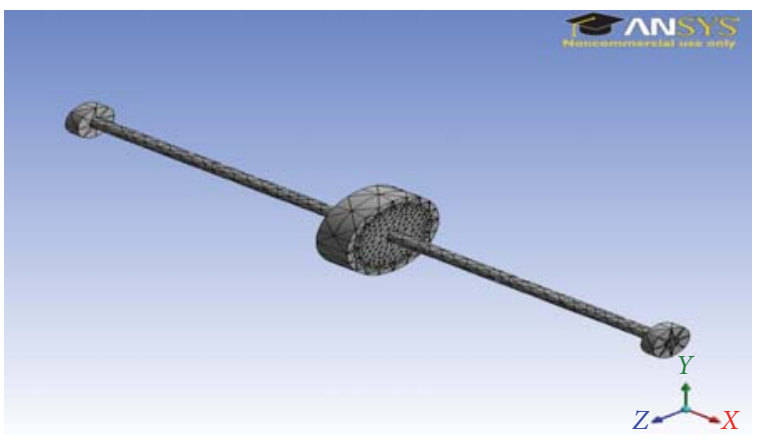

(b) (ANSYS) workbench, (3D).

FIGURE 5: Finite element modal rotating machinery (one disc, 3D).

vector. Substituting (2) into (1), the equation of spatial motions transformed into the equation of decoupled motion is obtained:
Multiplying the matrix $U^{T}$ at both sides of (3) produces the following:

$$
M U \ddot{\eta}+C U \dot{\eta}+K U \eta=f .
$$

$$
M \ddot{\eta}+\not, \dot{\eta}+\not K \eta=U^{T} f=\mu,
$$




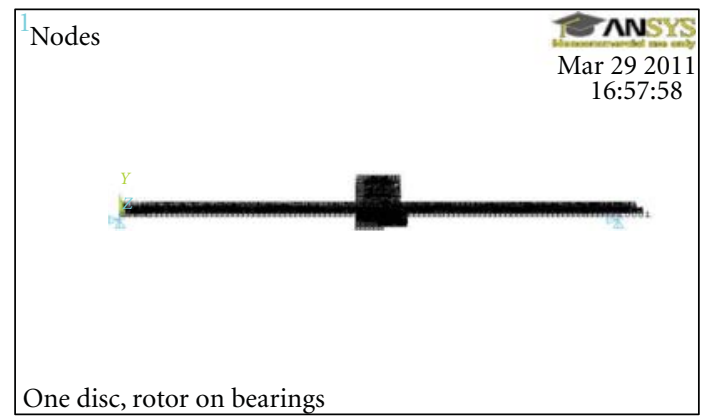

(a)

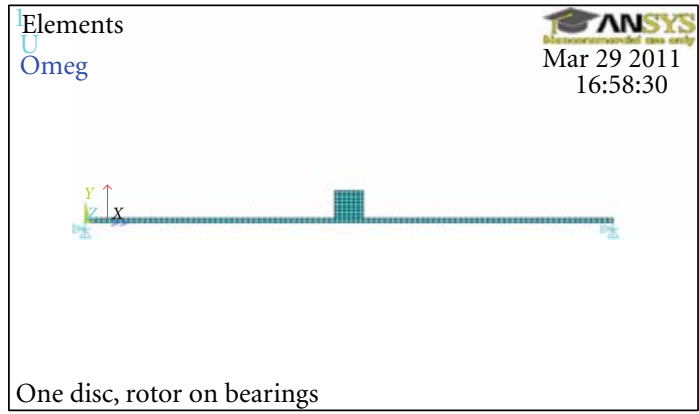

(b)

FIGURE 6: Finite-element model (FEM) rotating machinery ANSYS (APDL), two dimensions (2D).
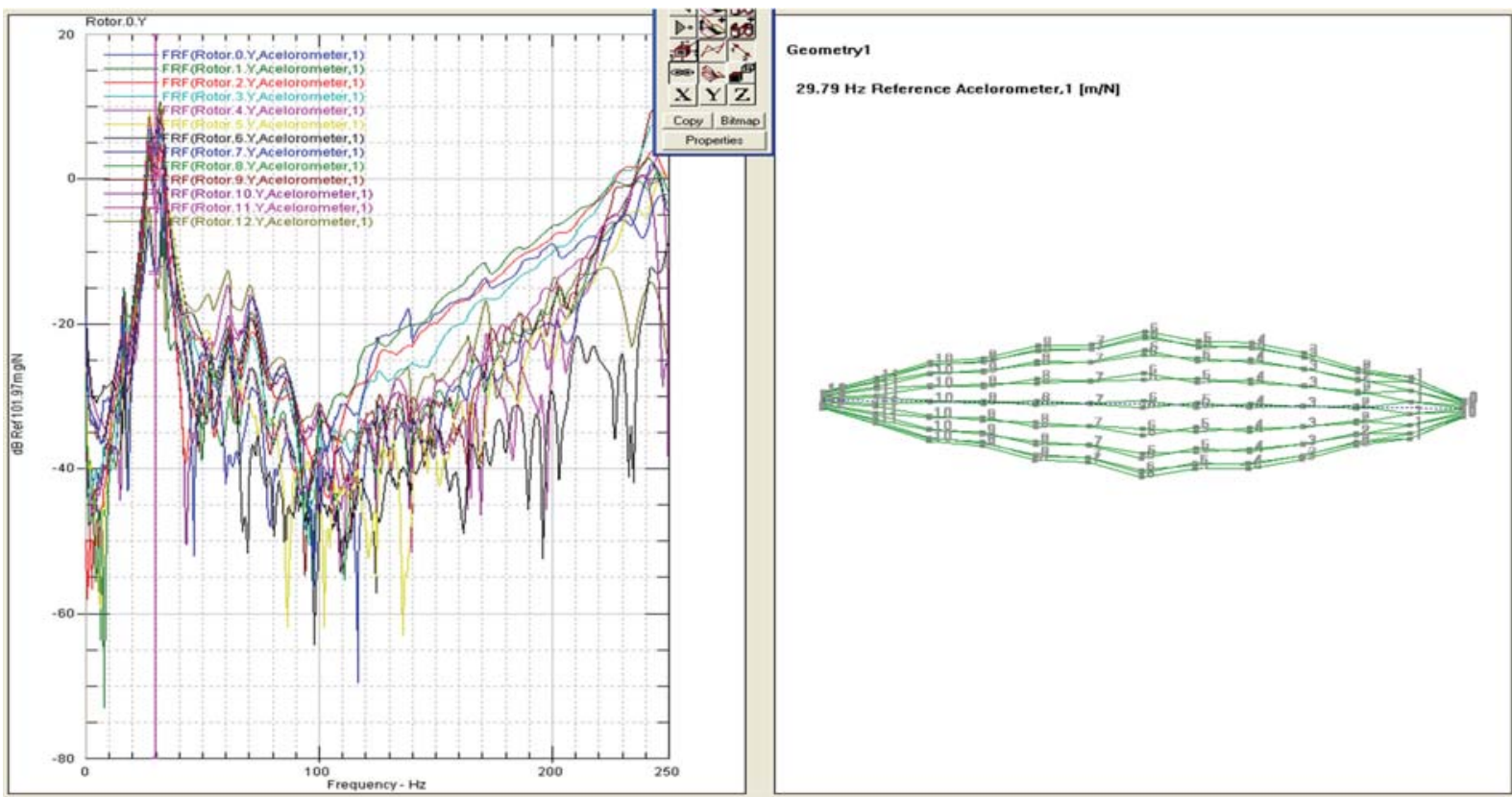

Figure 7: Stationary load in the middle, one disc (FRF) versus frequency (Hz), first mode shape. Natural frequency $29.79 \mathrm{~Hz}, \mathrm{range}(0-$ 500) $\mathrm{Hz}$.

where $M, \not$, and $K$ are the diagonal mass, damping, and stiffness matrices, respectively; and $\mu$ is the modal force vector. The equation of motion at the $r$ th mode is represented as follows:

$$
M_{r} \ddot{\eta}+C_{r} \dot{\eta}_{r}+K_{r} \eta_{r}=\mu_{r}
$$

where $\mu_{r}=\nu_{r}^{T}, f=\sum_{J=1}^{N} \varphi_{j r}$, and $f_{j}$ and $\varphi_{j r}$ the $j$ th components of the $r$ th mode shape vector. By considering the harmonic excitation acting on the system, the component to $f$ the modal coordinate, and the modal force at the $r$ th mode can be designated as $\eta_{r}=\eta e^{i \omega t}$ and $\mu_{r}=\hat{\mu}_{r} e^{i \omega t}$, respectively. Equation (2) becomes the summation of a series consisting of the exciting force, components of the mode shape, and the modal parameters:

$$
\begin{aligned}
\hat{x}_{N \times 1} & =\sum_{r=1}^{N} \hat{\eta}_{r} \nu_{r} \\
& =\sum_{r=1}^{N} \sum_{j=1}^{N} \frac{\varphi_{j r} \hat{f}_{j}}{M_{r}\left[\omega_{r}^{2}-\omega^{2}+2 i \omega \xi_{r} \omega_{r}\right]} \nu_{r},
\end{aligned}
$$

where $x=\hat{x} e^{i \omega t}$ is the displacement vector of the spatial model and $f_{j}=\hat{f}_{j} e^{i \omega t}$ is the exciting force. In addition, $\omega_{r}$ and $\zeta_{r}$ stand for the $r$ th natural frequency and damping ratio (called modal parameters), respectively. Considering just a 


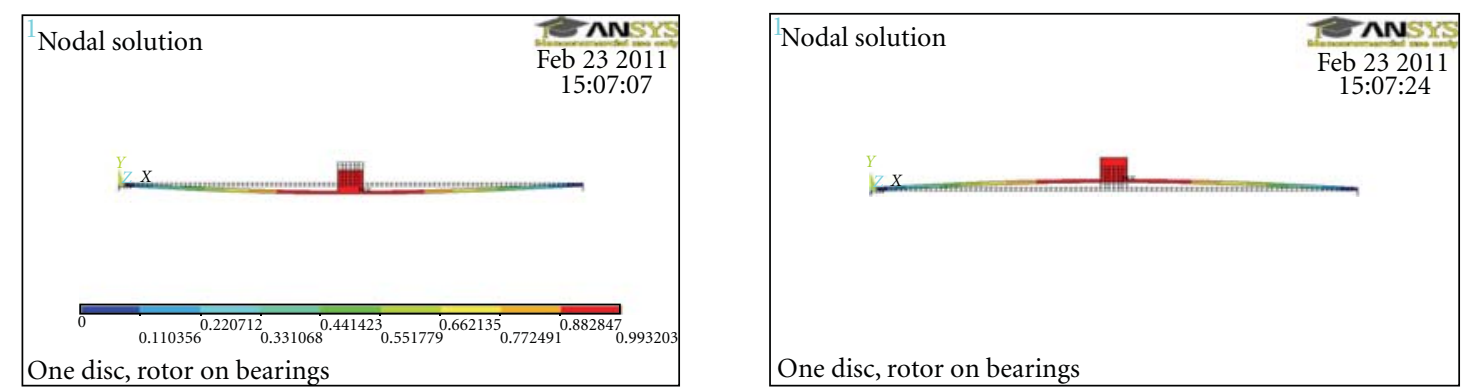

(a) Natural frequency $29.9393 \mathrm{~Hz}(2 \mathrm{D})$
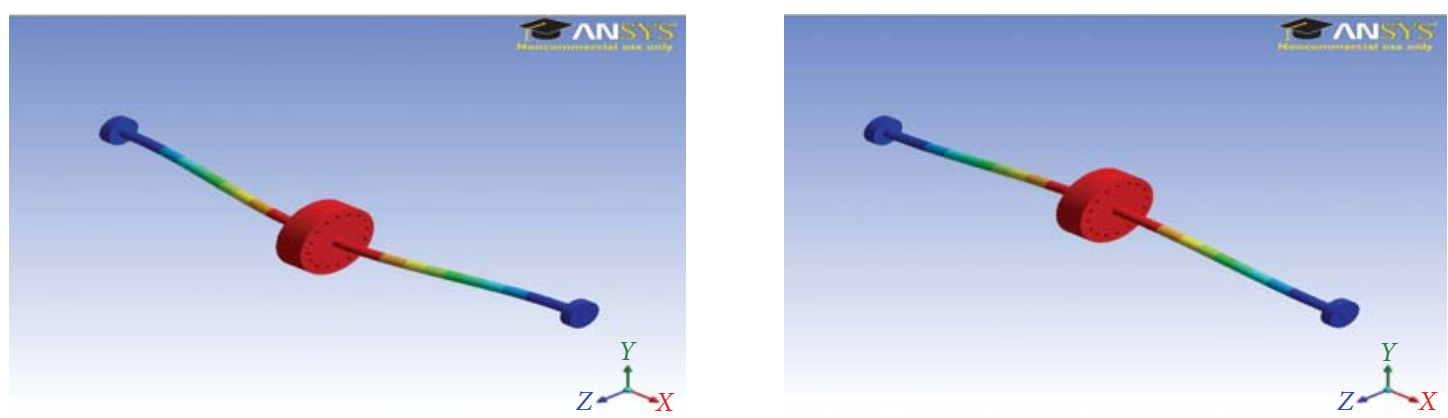

(b) Natural frequency $29.95 \mathrm{~Hz}$ (3D)

FIGURE 8: Finite-element method simulations, first mode shape, one disc with two bearings.

single component $\hat{f}_{j}$ of the exciting force, the $i$ th component of the displacement vector can be rewritten as

$$
\hat{x}_{i}=\sum_{r=1}^{N} \sum_{j=1}^{N} \frac{\varphi_{i r} \varphi_{j r} \hat{f}_{j}}{M_{r}\left[\omega_{r}^{2}-\omega^{2}+2 i \omega \xi_{r} \omega_{r}\right]} .
$$

The (FRF) $H_{i j}$ is defined as the ratio of the $i$ th displacement component $\hat{x}_{i}$ to the $j$ th exciting force component $\hat{f}_{j}$. It can also be shown as follows:

$$
\begin{aligned}
\frac{\hat{x}_{i}}{\hat{f}_{j}} & =H_{i j}=\sum_{r=1}^{N} H_{i j, r} \\
& =\sum_{r=1}^{N} \frac{\varphi_{i r} \varphi_{j r}}{M_{r}\left[\omega_{r}^{2}-\omega^{2}+2 i \omega \xi_{r} \omega_{r}\right]},
\end{aligned}
$$

where $H_{i j, r}$ is the peak value of FRF at the $r$ th mode. Equation (8) represents the relationship between the single exciting force and displacement. However, the situation of multiple excitations is not considered in the following theory.

3.1.2. The Pseudomode Shape Method. The simple system of a rotor-bearing-establishment system is shown above (see Figure 1) that demonstrates the (MBM) operation. The rotor was treated as the mother structure, while the foundation and two bearing supports were treated as the sub structure. Considering only the translation (DOF) sin the $Y$ and $Z$ directions at each of the bearing supports, the mode shape vectors of the bearing-foundation structure were represented with a total of four DOFs. Equation (8) involves the first four natural frequencies $(N=4)$ that can be expressed as follows [2]:

$$
\begin{aligned}
H_{i j}= & \frac{\varphi_{i 1} \varphi_{j 1}}{M_{1}\left[\omega_{1}^{2}-\omega^{2}+2 i \omega \xi_{1} \omega_{1}\right]}+\frac{\varphi_{i 2} \varphi_{j 2}}{M_{2}\left[\omega_{2}^{2}-\omega^{2}+2 i \omega \xi_{2} \omega_{2}\right]} \\
& +\frac{\varphi_{i 3} \varphi_{j 3}}{M_{3}\left[\omega_{3}^{2}-\omega^{2}+2 i \omega \xi_{3} \omega_{3}\right]}+\frac{\varphi_{i 4} \varphi_{j 4}}{M_{4}\left[\omega_{4}^{2}-\omega^{2}+2 i \omega \xi_{4} \omega_{4}\right]},
\end{aligned}
$$

where $i=1,2, \ldots, 4$ and $j=1,2, \ldots, 4$. Assume that the first term at the right-hand side of (9) was dominant in affecting the values of the (FRFs) when $\omega=\omega_{1}$ whereas the other terms had a weak influence on these FRFs. Thus, the second, third, and fourth terms can be omitted. The simplified form of (9) can now be presented as follows:

$$
H_{i j, 1}=\frac{\varphi_{i 1} \varphi_{j 1}}{M_{1} 2 i \xi_{1} \omega_{1}^{2}} .
$$

As mentioned, with two DOFs at each of two bearing supports, there were a total of four (DOFs) for all of the supports of the whole system [10]. After this, a $(4 * 4)$ symmetric frequency response function matrix was built as follows:

$$
\text { FRF matrix }=\left[\begin{array}{lllll}
H_{11, r} & & & \\
H_{21, r} & H_{22, r} & & \\
H_{31, r} & H_{32, r} & H_{33, r} & \\
H_{41, r} & H_{42, r} & H_{43, r} & H_{44, r}
\end{array}\right] .
$$

At the first mode $(r=1)$, the available peak values in the (FRF) data were denoted as $H_{11,1}, H_{21,1}, H_{31,1}, H_{41,1}, H_{22,1}$, $H_{32,1}, H_{42,1}, H_{33,1}, H_{43,1}$, and $H_{44,1}$. These values can then be utilised to evaluate the related components. 

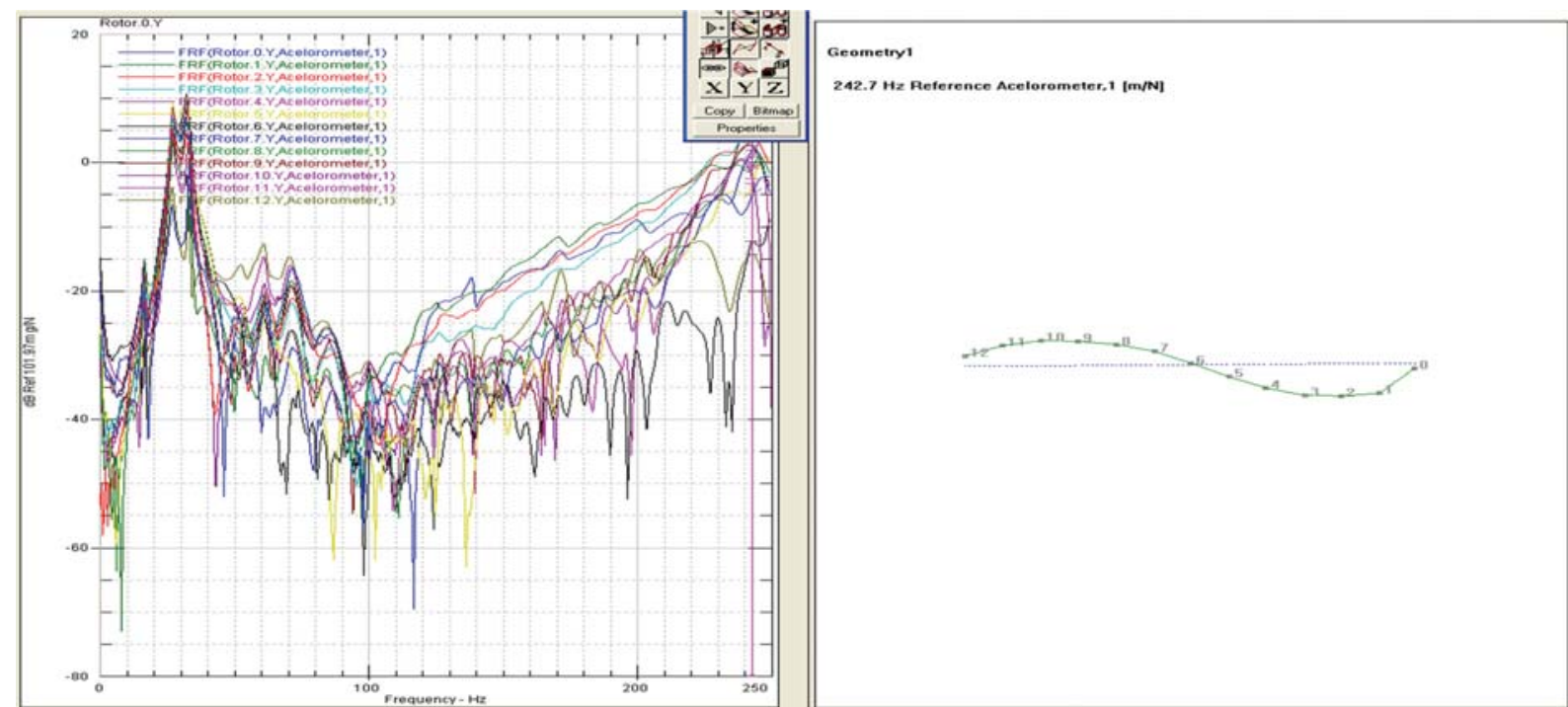

Figure 9: Stationary load in the middle, (FRF) versus frequency $(\mathrm{Hz})$, one disc, second mode shape. Natural frequency $242.7 \mathrm{~Hz}$, range $(0-500) \mathrm{Hz}$.
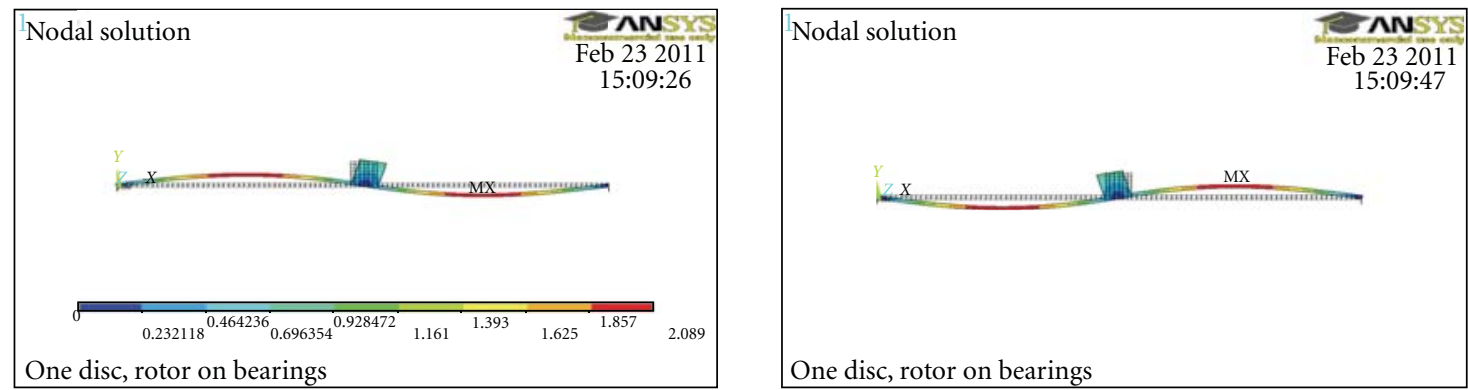

(a) Second mode shape, natural frequency $243.71 \mathrm{~Hz},(2 \mathrm{D})$
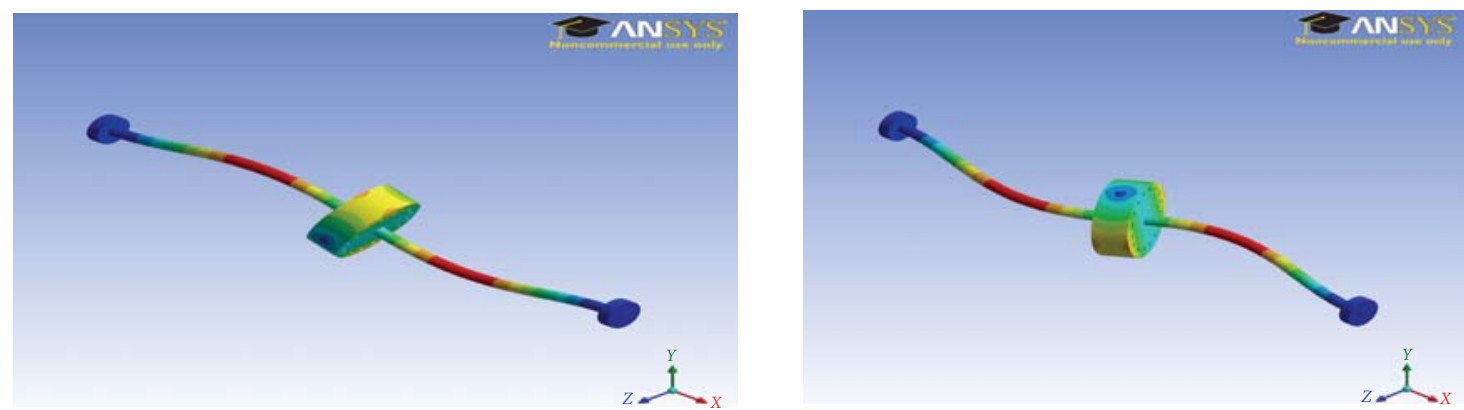

(b) Second mode shape, frequency $243.68 \mathrm{~Hz},(3 \mathrm{D})$

FIGURE 10: Finite-element method, simulations one disc with two bearings.

3.2. Revolve Acquisition and Analysis Investigational. The rotate acquisition and analysis software package is part of $(m+p$ international's). It is designed for troubleshooting and analyzing noise or vibration problems related to the speed characteristics of rotating or reciprocating components of a machine in operation $[10,11,13]$.
3.2.1. Experiment Setup. Experimental modal analysis has grown steadily in popularity since the advent of the digital FFT spectrum analyser in the early 1970's. Today's impact testing (or bump testing) has become widespread as a fast and economical means of finding the modes of vibration of a machine or structure. The test rotor is shown in Figure 2. 


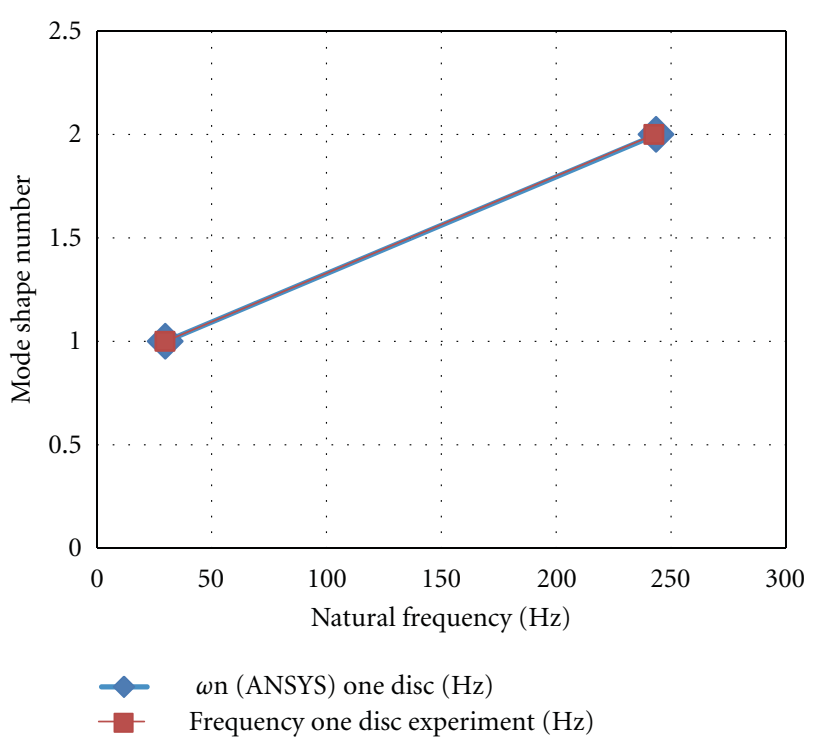

FIgURE 11: Natural frequency experiment with ANSYS, (one disc).

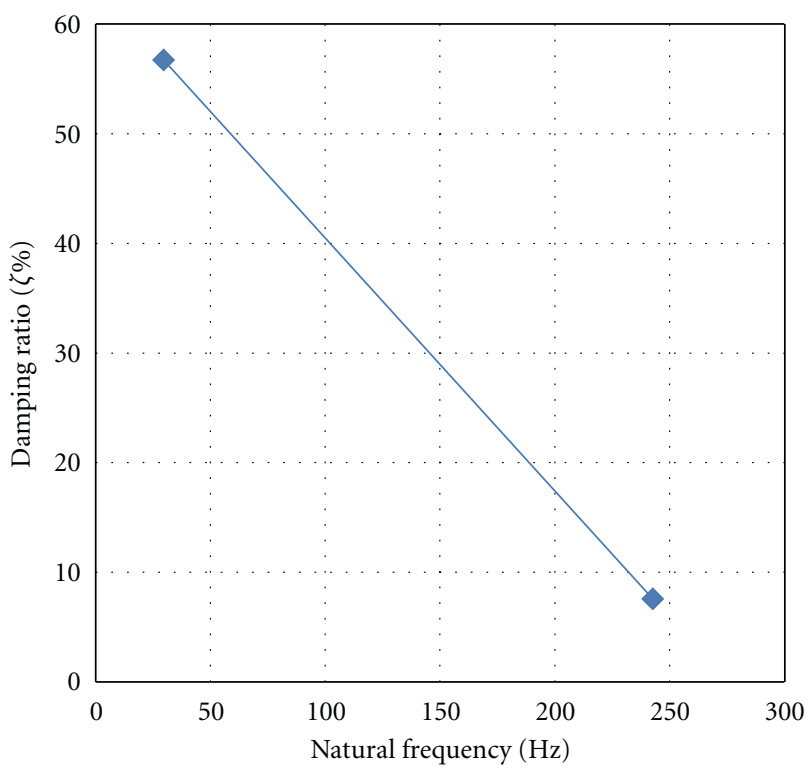

Damping ratio versus, natural frequency

$(0-500) \mathrm{Hz}$, accelerometer fix, one disc

FIGURE 12: Damping ratio $(\zeta)$ versus natural frequency $(0-500) \mathrm{Hz}$, one disc.

Basically, the rotor consisted of a shaft with a nominal diameter of $10 \mathrm{~mm}$, with an overall length of $610 \mathrm{~mm}$. Two plain bearings, RK4 Rotor Kit made by Bentley Nevada (the advanced power systems energy services company), are used to extract the necessary information for diagnostic of rotating machinery, such as turbines and compressor. The testing of the process will be conducted on the rotary machine as the project is based on rotary dynamics reach practical results for the purpose of subsequently applied machinery rotary by using (Smart Office program). It is the software which is used

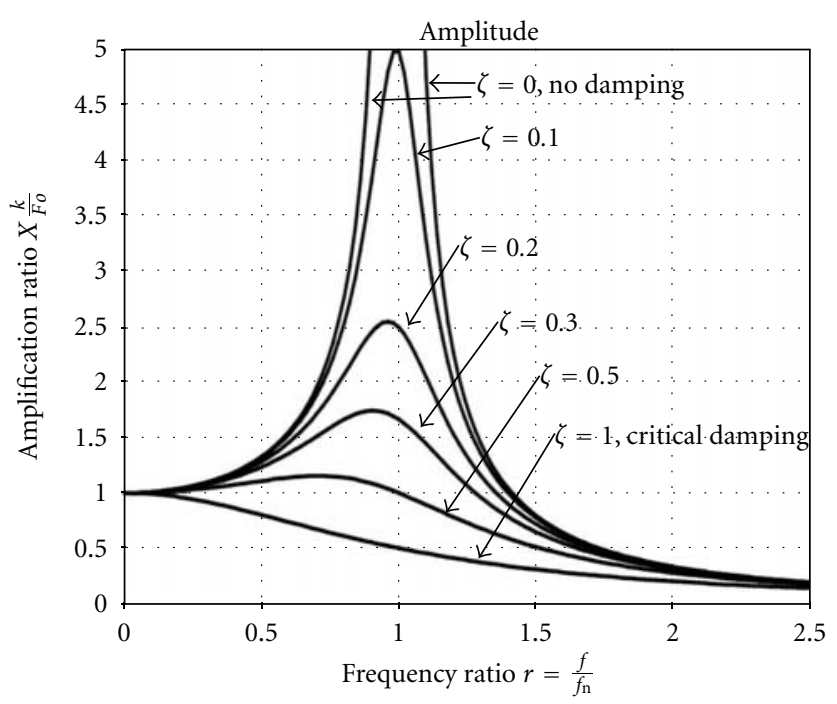

FIgURe 13: Amplification ratio versus $r$ [3].

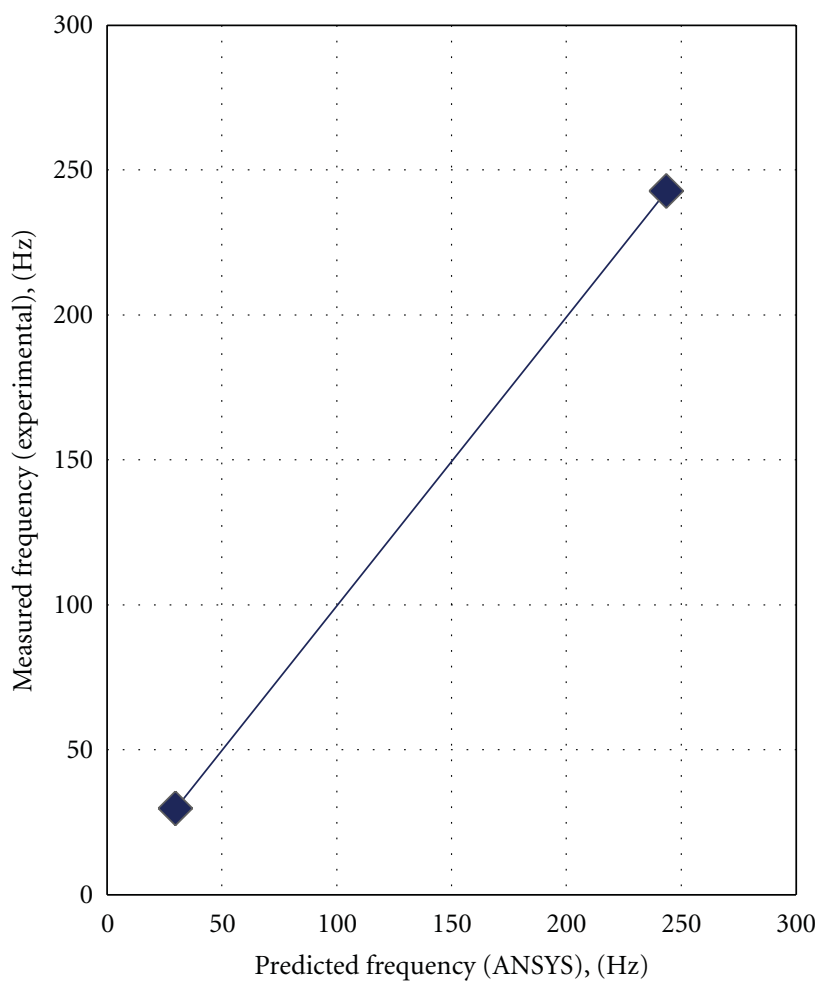

Comparison between measured and predicted natural frequency $(\mathrm{Hz})$

FIGURE 14: Comparison between measured \& predicted frequency $(\mathrm{Hz})$.

in this project [14]. The analyzer is suitable for accurate and efficient noise and vibration measurements, third-party data import/export, data analysis, and reporting of the results. The SO analyzer supports a wide range of measurement front-end (USB, PCI, PX1, and VX1) which enables the applications (from two to hundreds of input channels). 


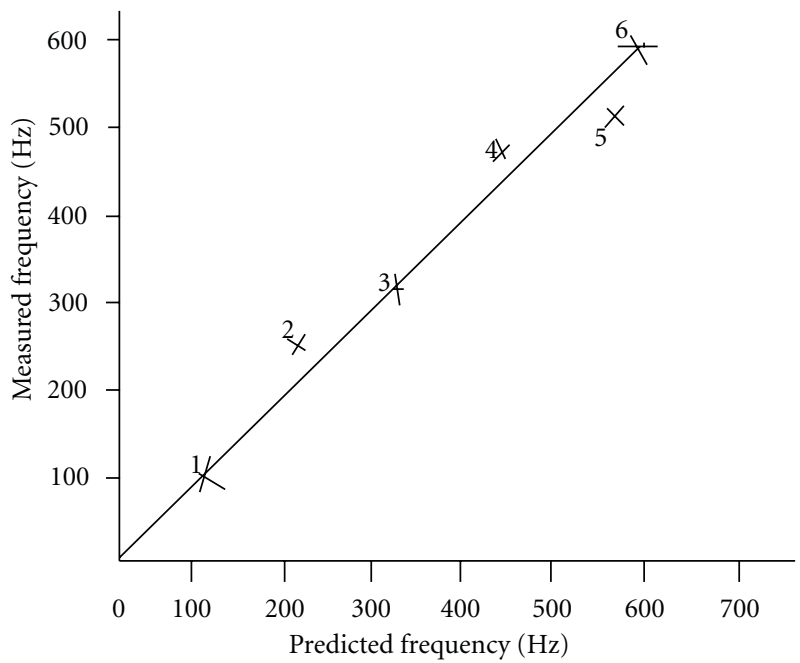

Figure 15: Measured and predicted frequency $(\mathrm{Hz})$ [9].

Then, do the experimental testing using the impact test, installed fixed two accelerometer (model 333B32, sensitivity 97.2 and $98.6 \mathrm{mV} / \mathrm{g}$ ) in $\mathrm{Y}-\mathrm{Z}$ direction and roving the hammer (model 4.799.375, S.N24492) on each point for the purpose of generating strength of the movement for the vibration body and the creation of vibration for that with creating a computer when taking readings in file that was dimensions and introducing it with the data within the program Smart office to look for mode shape, see Figure 3. $[10,15]$. Configurations of testing on the rotary machines, all necessary equipment for test were shown with the geometry design wizard (see Figure 4).

3.3. Simulation of Model. A model of rotor system one disc with multidegree of freedom ( $Y$ and $Z$ directions) has been used to demonstrate the above capability Figures 5 and 6 . Program has been written in ANSYS 12, Postprocessing commands (/POST26). Applying of gyroscopic effect to rotating structure was carried by using CORIOLIS command. This command also applies the rotating damping effect. CMOMEGE specifies the rotational velocity of an element component about a user-defined rotational axis. (OMEGA) specifies the rotational velocity of structure about global Cartesian axes. Model the bearings using a spring/damper element (COMBIN 14). Another command used input file (SYNCHRO) which specifies whether the excitation frequency is synchronous or asynchronous with the rotational velocity of a structure in a harmonic analysis [11]. The finiteelement (FE) method used in ANSYS offers an attractive approach to modeling a rotor dynamic system.

In the sections that follows, modeling details and analysis procedures for a rotating structure are detailed. Generally, a 3D model directly available from the CAD can be used for the analysis Figure 5; however, 3D models result in a large number of nodes and element models. This paper demonstrates how to extract a plane 2D model (Figure 6) from the $3 \mathrm{D}$ model (Figure 5), which can be analyzed using far fewer nodes and elements. The ease of use, accuracy, and performance of 2D and 3D model analyses are closest match each other when in comparison with experiment test. Rotor dynamics play a crucial role in identifying critical speeds and to ultimately design rotating structures that tolerate extremely high vibrations. This example illustrates the application of rotor dynamics analysis procedures using the Nelson-Vaugh rotor model $[11,16,17]$.

A $2 \mathrm{D}$ axisymmetric representation of the $3 \mathrm{D}$ solid model is used to perform a rotor dynamic analysis. The results of the $2 \mathrm{D}$ axisymmetric model analyses are closest match to the full 3D solid model results $[16,18,19]$.

\section{Results}

As it can be seen from the experimental one disc in the middle first mode (Figure 7) and FE simulation (Figures 8(a) and $8(\mathrm{~b})$ ), the result of natural frequency and mode shape closest match each other, as the same with (Figures 9, 10(a), and $10(\mathrm{~b})$ ) the second mode, we see all the results closest match each other between the experimental and simulation (ANSYS), we can see the result in Table 1 and Figure 11 for comparison. Frequency response function (FRF) of the rotor was found using the impact test mechanism and Smart Office software. As it can be seen from figures below different mode shape for the range $(0-500) \mathrm{Hz}$, the experiment shows that by applying a negligible excessive loading to the system the value of the natural frequency mode shape does not changes significantly for different speed.

we find the damping ratio $(\zeta)$ for different mode shape by curve fitting [20], (multi degree of freedom system) in experimental part, (Table 2) and (Figure 12). We draw graph comparison between measured (experimental) and prediect natural frequency (ANSYS), (Figure 14) show the slope approximately nearby from $45^{\circ}$. With further simulation we find the relation between the reaction forces with respect time can be seen from Figures 16(a), 16(b), 16(c) and 16(d). The performance of reaction forces in the right and left bearings with different speed of rotations. 


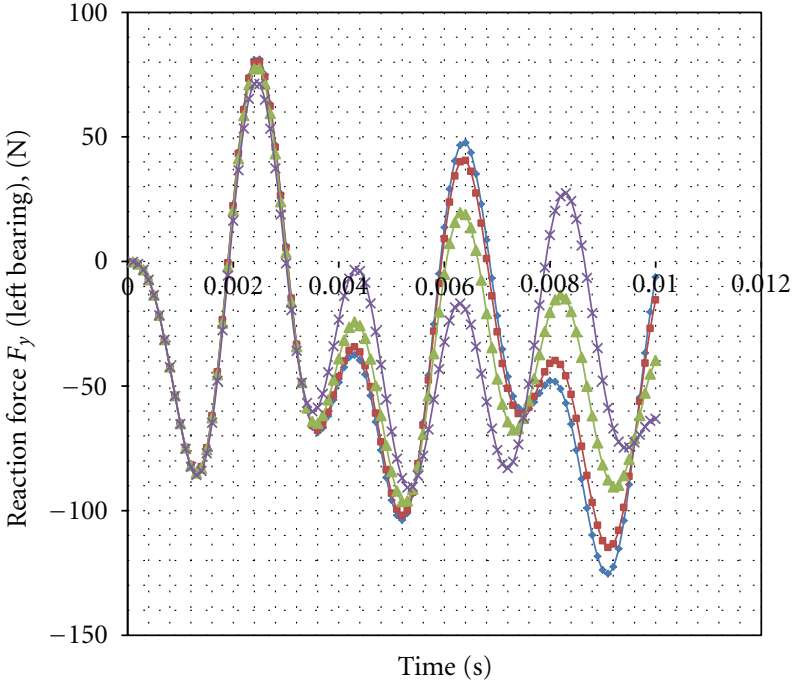

(a) Reaction force $\left(F_{y}\right)$ left bearing
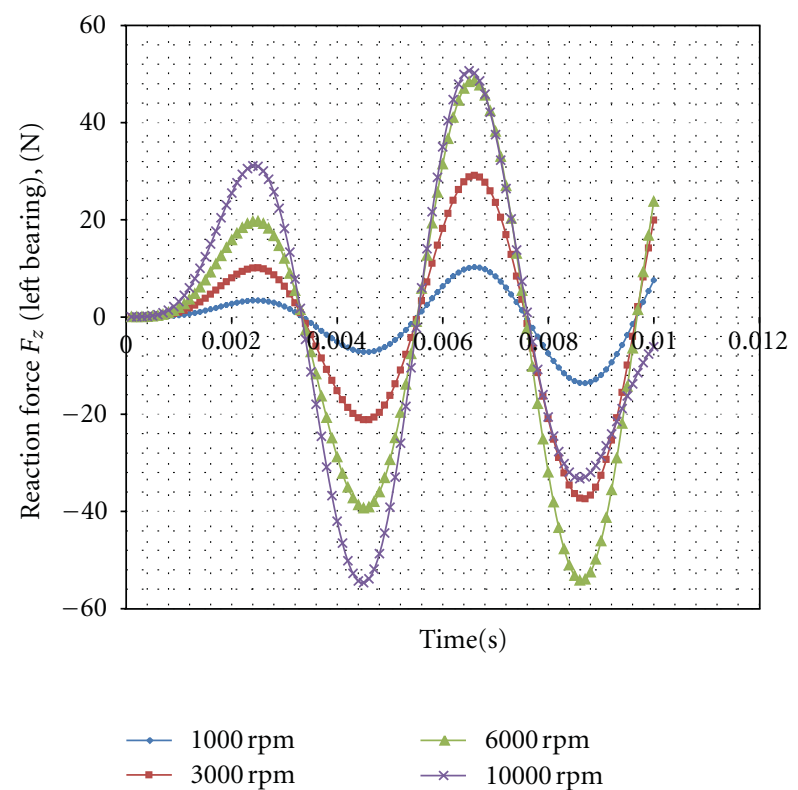

(c) Reaction force $\left(F_{z}\right)$ left bearing

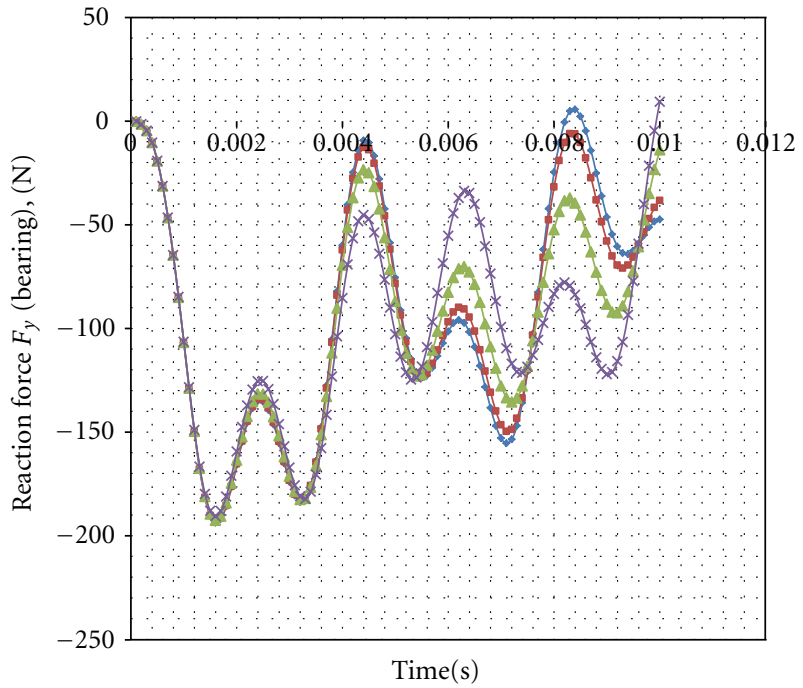

(b) Reaction force $\left(F_{y}\right)$ right bearing

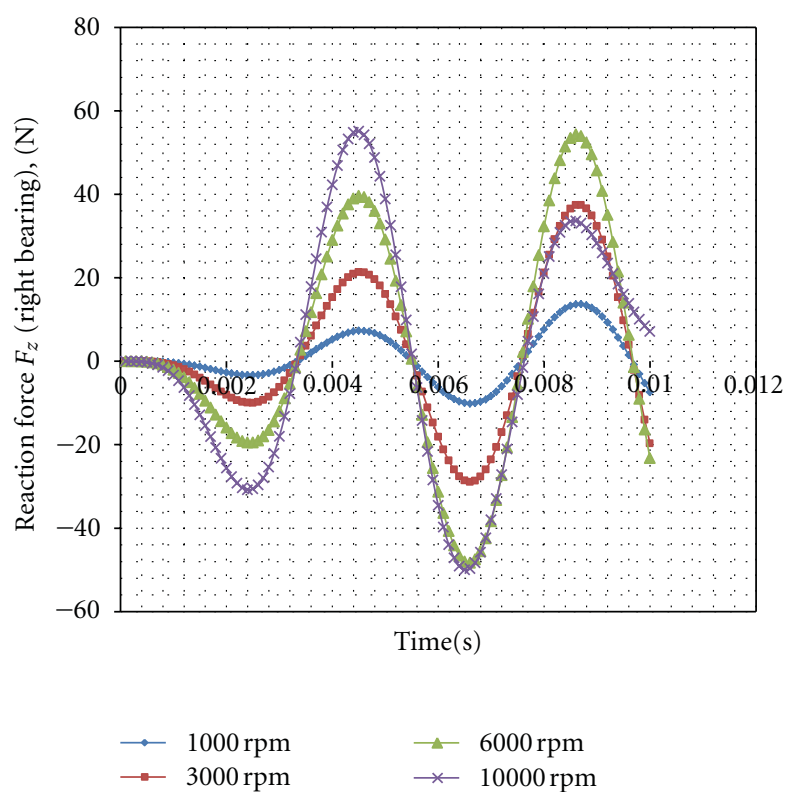

(d) Reaction force $\left(F_{z}\right)$ right bearing

FIGURE 16: Relation between reaction force bearings versus time at different speed of rotation (one disc in the middle).

TABle 1: Comparison between natural frequency outcomes from experiment \& ANSYS, (one disc).

\begin{tabular}{lccc}
\hline $\begin{array}{l}\text { Mode } \\
\text { shape }\end{array}$ & $\begin{array}{c}\omega_{n} \text { (ANSYS) } \\
\text { one disc }(\mathrm{Hz})\end{array}$ & $\begin{array}{c}\text { Frequency one } \\
\text { disc experiment } \\
(\mathrm{Hz})\end{array}$ & Error \% \\
\hline 1 & 29.939 & 29.79 & 0.497678613 \\
2 & 243.71 & 242.74 & 0.398014033 \\
\hline
\end{tabular}

As it can be seen from the experimental (Figures 17, 18 and 19) and FE simulation, when 8 gram of excessive load is added to the loading of the system, the excessive loading is away from the centre of the shaft by $(30 \mathrm{~mm})$,
TABLE 2: Natural frequency and damping ratio $(\zeta)$ for one disc range $(0-500) \mathrm{Hz}$ (experimental part).

\begin{tabular}{lccc}
\hline $\begin{array}{l}\text { Frequency } \\
(\mathrm{Hz})\end{array}$ & $\begin{array}{c}\text { Damping ratio } \\
(\zeta) \%\end{array}$ & Modal A $[\mathrm{kg} / \mathrm{s}]$ & Name \\
\hline 29.79 & 56.701 & $0.009123329-(0.01562434)$ & Mode1 \\
242.74 & 7.561 & $0.001488148-$ & Mode 2 \\
\hline
\end{tabular}

load added in the disc groove by angle $\left(135^{\circ}, 315^{\circ}\right)$ degree, frequency response functions (FRFs) of the rotor has found it. With further simulation, we find the relation between the bending stress with respect of time (Figures 21(a), 21(b)), the 


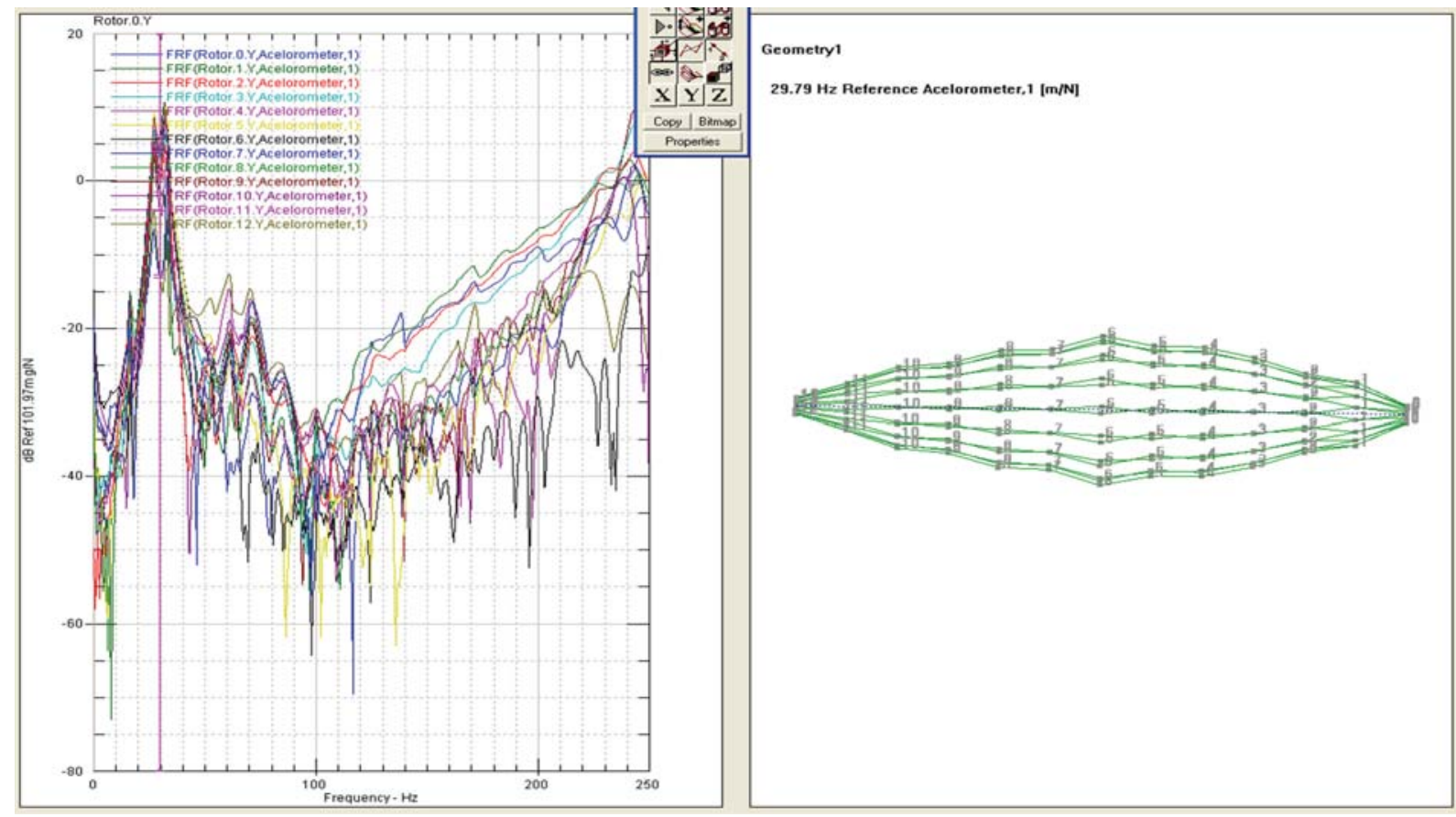

(a) Before add mass

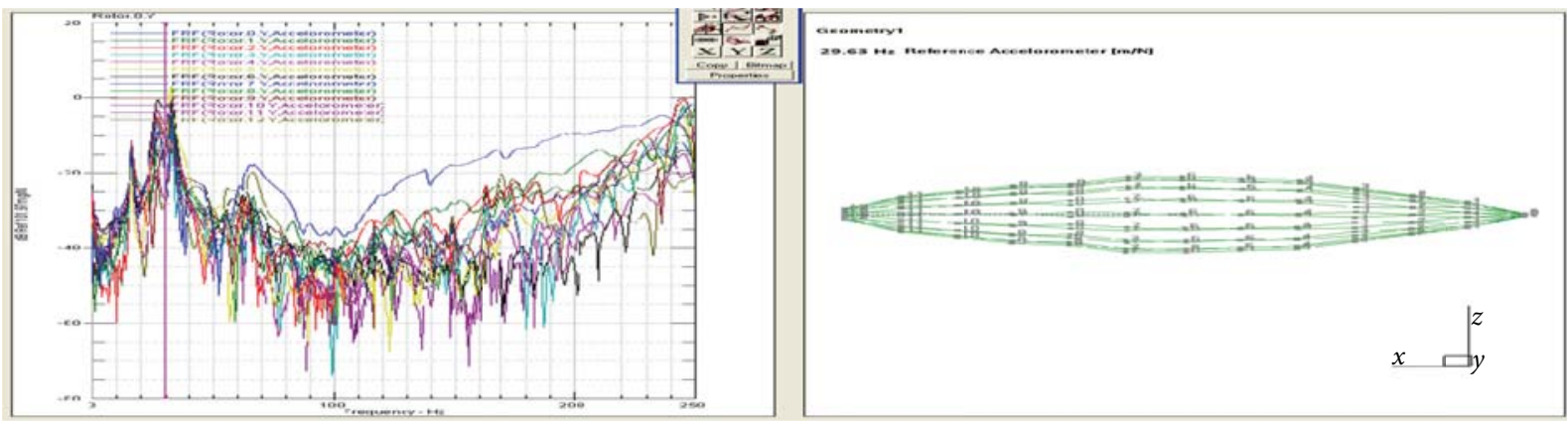

(b) After add mass $\left(8\right.$ gram at $135^{\circ}$ and $\left.315^{\circ}\right)$ in the disc speed of rotation $1000 \mathrm{rpm}$

FIGURE 17: Stationary load in the middle (FRF) versus frequency (Hz), speed of rotation $1000 \mathrm{rpm}$ (first mode shape).

performance of bending stresses at one disc in the middle we see before added 8 gram mass and after.

4.1. Modelling Effect (One Disc in the Middle). (See Figures 7-15).

4.2. Reaction Forces in the Left and Right Bearings (One Disc). (See Figure 16).

4.3. Unbalance Effect. Add the mass at speed of rotation $1000 \mathrm{rpm}$, (one disc in the middle). (See Figures 17 and 18).

Add the mass at speed of rotation $4000 \mathrm{rpm}$, (one disc in the middle) (See Figure 19).

\subsubsection{ANSYS Results. (See Figures 20 and 21).}

4.4. Operational Deflection Shapes. (See Figures 22-23).
4.5. Effect of Change Diameter of Disc (Mass) to the Natural Frequency. (See Figure 24).

\section{Discussion and Conclusions}

In this paper, the behaviour of a rotor system with stationary load in the middle (one disc) was investigated. Modern experimental modal analysis techniques have been reviewed in this paper. The three main topics pertaining to modal testing, (FRF) measurement techniques, excitation techniques and modal parameter estimation (curve fitting) methods were covered. To conclude, the related knowledge as obtained in the study has drawn up a technical basis for better commanding the design quality of the induction motor. The developed solution modules have features of performing multipurpose rotor dynamic analyses for the characteristics of the rotating machines. The application case addressed in this study has just shown its advantageous strength in solving 


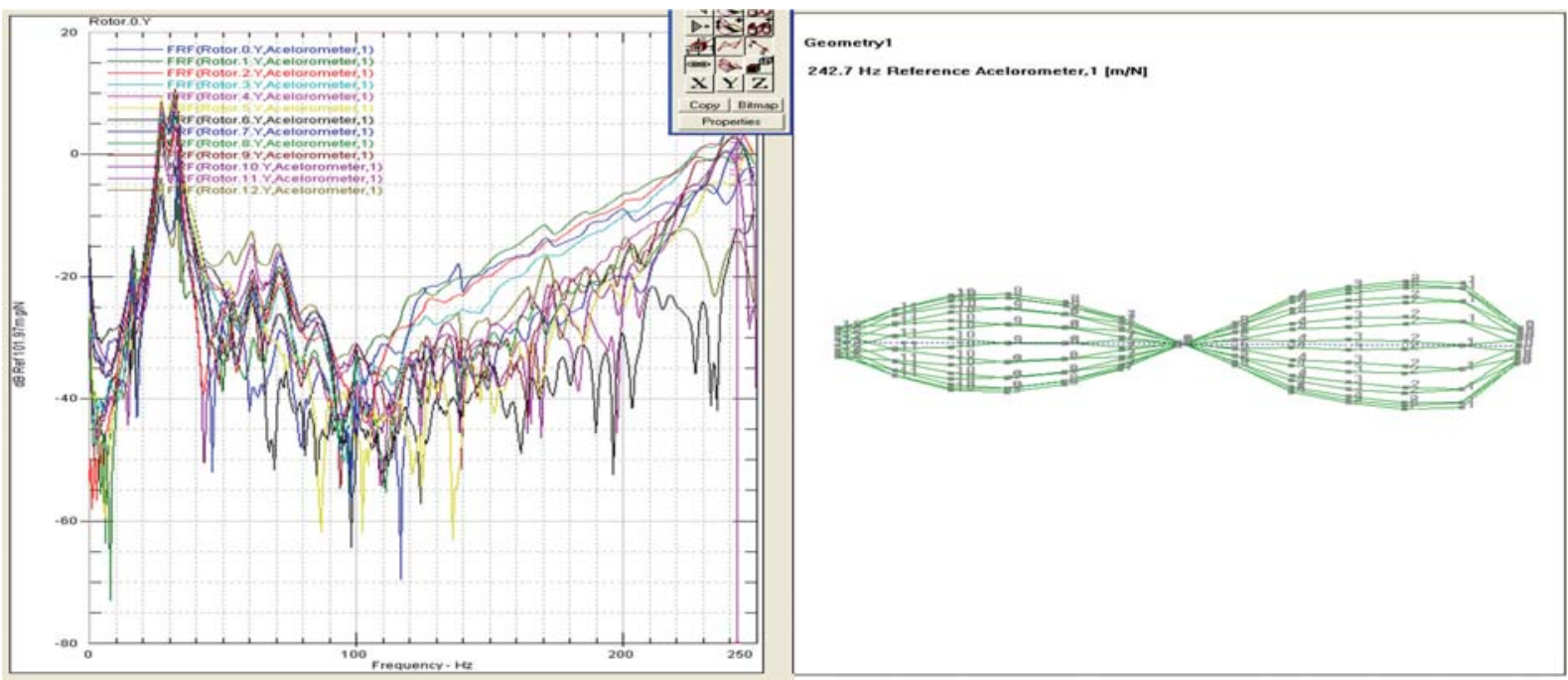

(a) Before add mass

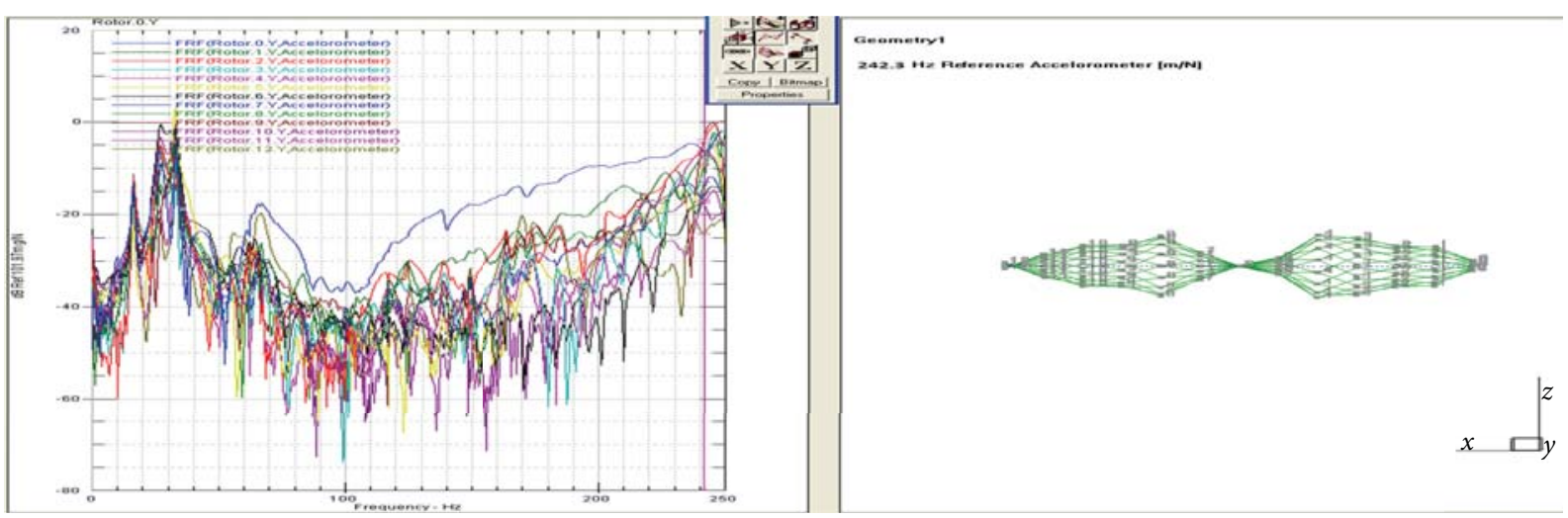

(b) After add mass $\left(8\right.$ gram at $135^{\circ}$ and $\left.315^{\circ}\right)$ in the disc

FIGURE 18: Stationary load in the middle, (FRF) versus frequency $(\mathrm{Hz})$, speed $1000 \mathrm{rpm}$ (one disc, second mode shape).

the realistic problem of the shaft failure for the electric machine. It is especially beneficial for the design of reliable and high-quality high-speed spindle machinery. Further improvement and validation of the developed software system can solve some other rotating spindle problems such as those potential problems in improving the cutting efficiency by raising the working speeds of the current ultra high speed gas bearing spindles.

The purpose of the modified and described in this paper is to solve real-world engineering problems. Using the limited (FRF) data, engineers obtain the equivalent substructure model while avoiding tedious (FE) modelling processes. By associating the method with other applications, it can have a wide range of practical advantages, such as developing the online diagnostics of rotor system by improving its computer simulation efficiency.

The simulation values obtained from the ANSYS (Figures $8,10)$ in one disc to find natural frequency and draw mode shape are perfectly nearby to approval values obtained from the experimental that (Figures 7,9) for first and second mode shapes, one disc. Comparison values with ANSYS are shown in Table 1 above and are clear (Figure 11).
From all (Figure 12) notes the decreased damping ratio caused increased natural frequency until reach maximum amplitude when the system reaching resonance $\omega=\omega_{n}$, when damping ration $(\zeta$ approx., $=0)$, free vibration is clear in (Figure 13) [3].

To compare the natural frequency, this is often done by a simple tabulation of the two sets of results but a more useful format is by plotting the experimental value against the predicted on for each of the modes included in the comparison (Figure 14). In this way, it is possible to see not only the degree of correlation between the two sets of results but also the nature (and possible case) of any discrepancies which do exist. The points plotted should lie on or close to straight line of slope (Figure 15), [9], if it lies close to a line with different slope, then almost certainly the cause of the discrepancy is an erroneous material property used in the predictions. If the point lies scattered widely about straight line, then there is serious failure of the modal to represent the test structure and fundamental reevolution is called for. If the scatter is small and randomly distributed about $45^{\circ}$ line, then this may be expected from normal modelling and measurement process (Figure 14). A case of particular 


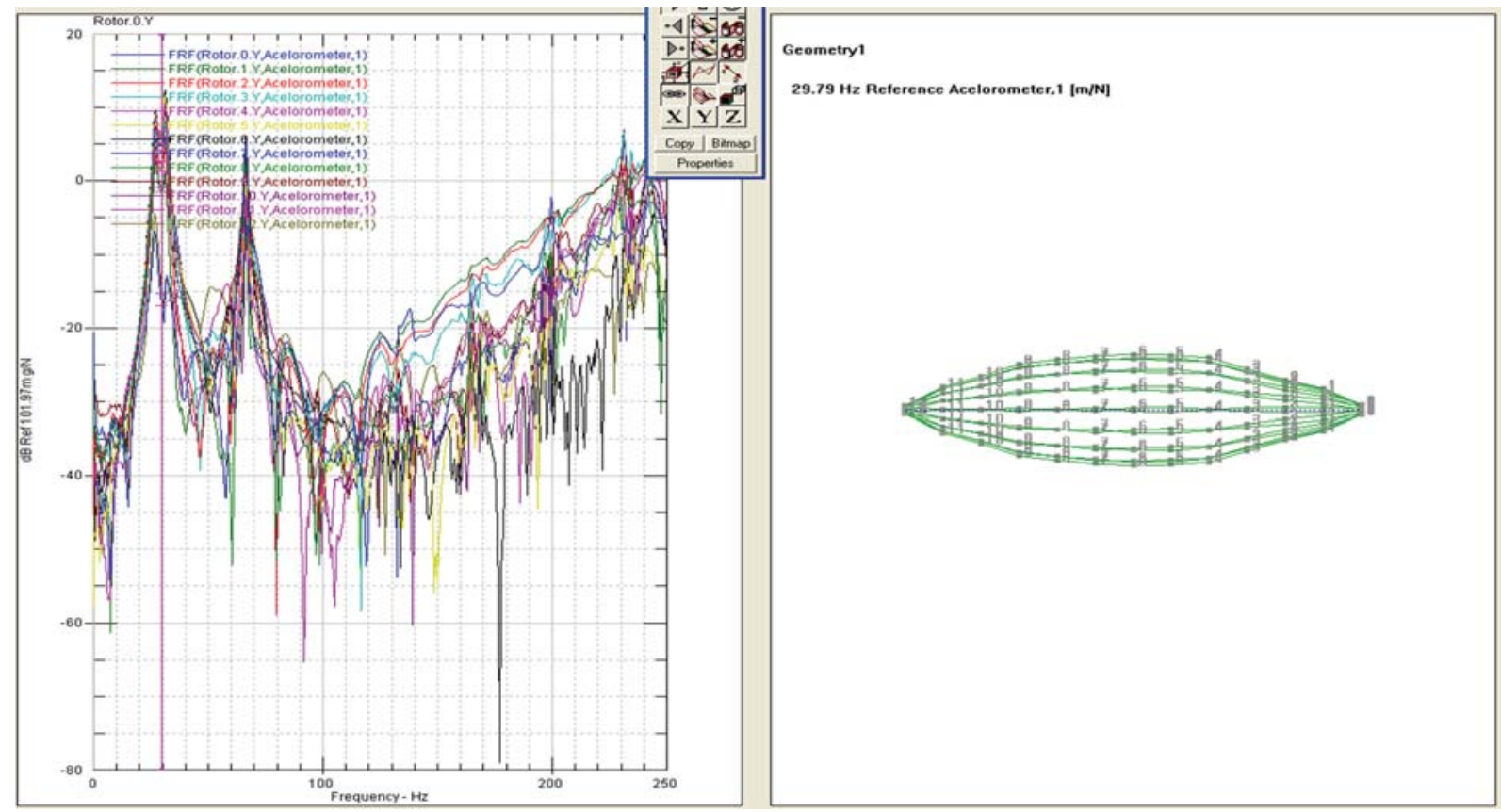

(a) (FRF) versus frequency $(\mathrm{Hz})$, before add mass

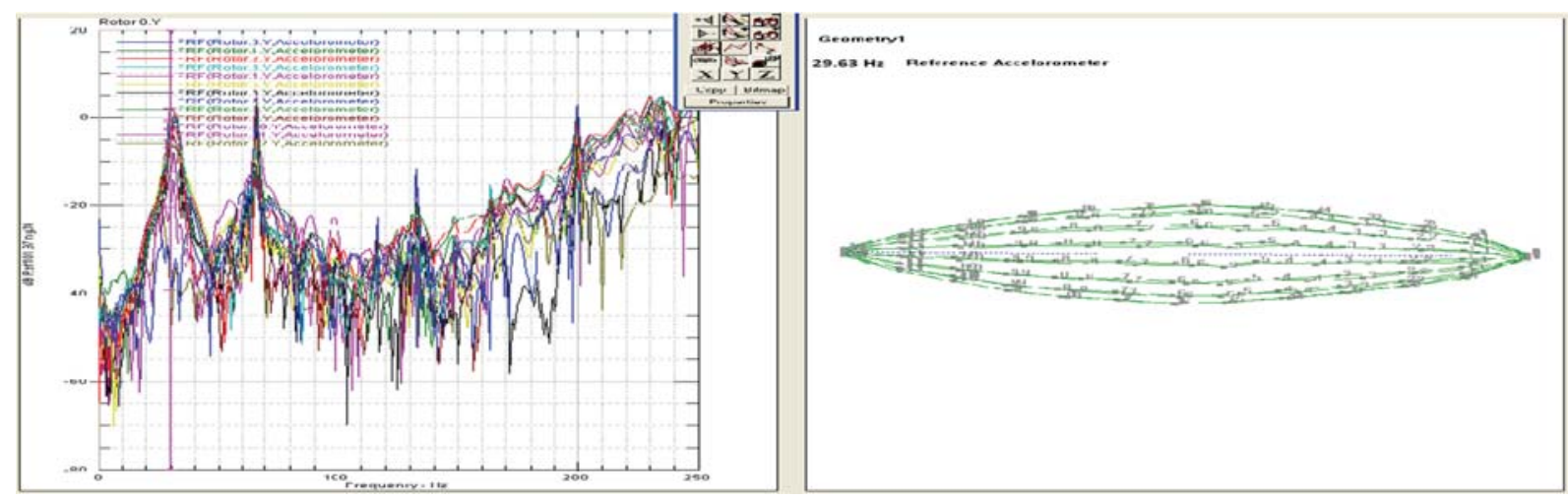

(b) After add mass $\left(8\right.$ gram at $\left.135^{\circ}, 315^{\circ}\right)$ in the disc

FIgURE 19: Stationary load in the middle (one disc first mode shape), speed $4000 \mathrm{rpm}$.

interest is where the points deviated slightly from the ideal line but in a systematic rather than a random fashion as this situation suggests that there is specific characteristic responsible for the deviation and that this cannot simply be attributed to experimental error.

For further studies, there is no need to produce experimental analysis about this study as numerical analysis using ANSYS produces accurate results. We used (ANSYS) to find the relation between the reaction-bearing forces $(N)$ with respect to time, see Figure 16. The performance of reaction bearing forces (Figures 16(a), 16(b), 16(c) and 16(d)) in the right and left bearings with different speed is seen when increasing speed of rotation, the reaction force increases for both right and left bearings when increasing the speed of rotation but from the figures above, we see the maximum reaction force in $Y$ direction in left and right bearings when the motor runs up, after a few second it become decreasing while the reaction in $Z$ direction has begun increasing slowly in left and right bearings until reaching maximum value when the speed is increasing. That means we must take care to right bearing when run up the motor because this bearing carries maximum reaction force at the begining. During study, this performance of reaction force in both bearings can aid in the design of low-noise rotor-bearing systems and reduce the reaction force in the bearing to make the bearings long save life by lubrication. In order to investigate the effects of design parameters on the noise of rotor-bearing systems, the effects of radial clearance and width of bearing, lubricant viscosity, for various rotational speeds, it is found that, as a general rule, the noise of the bearing decreases as the lubricant viscosity increases, the width of the bearing increases, and the radial clearance of the bearing decreases.

The locations of the adding balanced masses by suppressing the vibration amplitudes are decided to be at the 


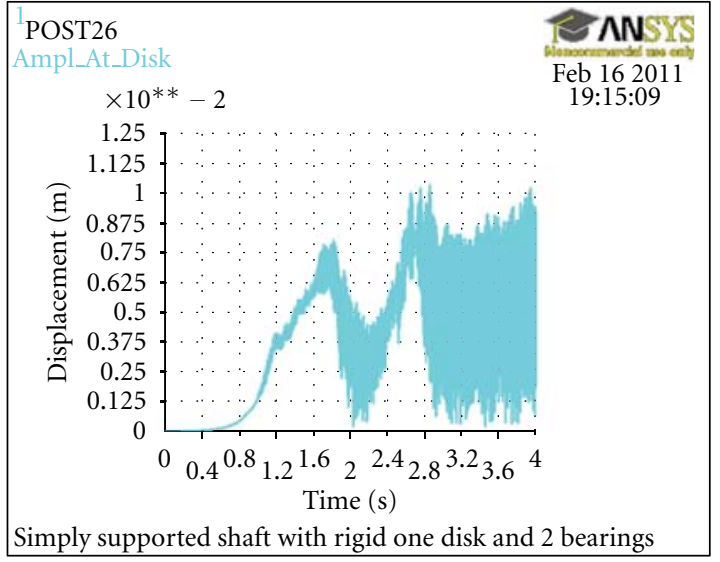

(a) Displacement versus time before add mass

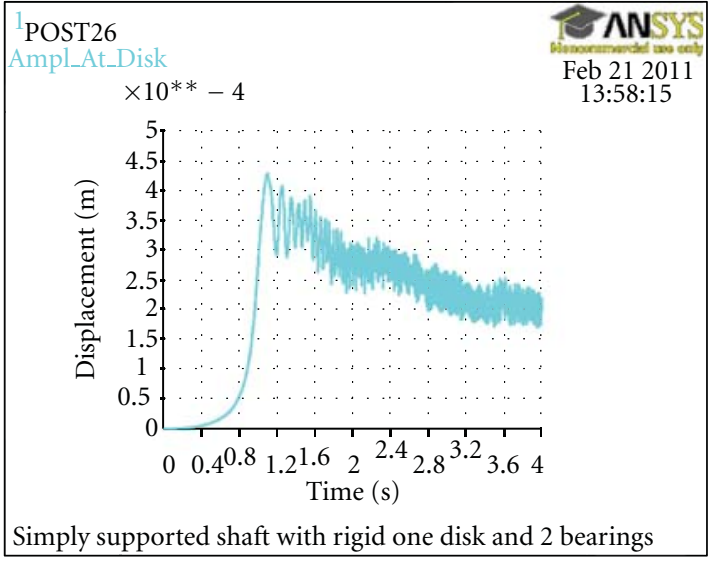

(b) Displacement versus time after add mass 8 gram

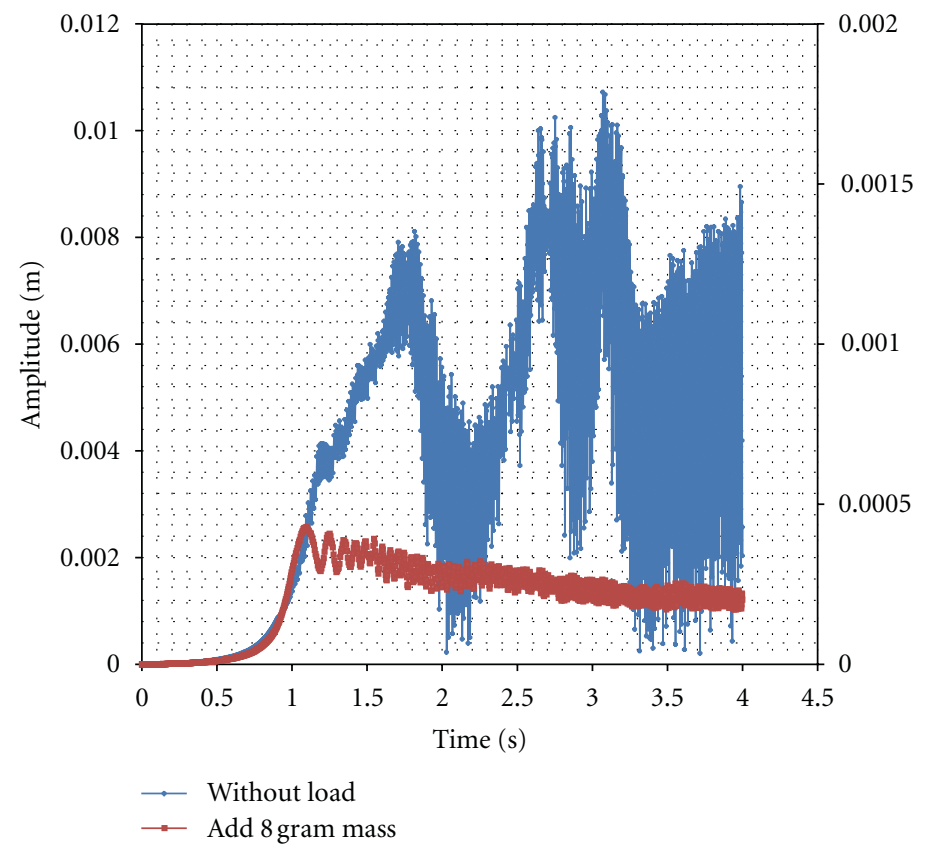

(c) Merge comparison

FIgure 20: Amplitude versus time, (a) without load, (b) after add 8 gram mass, (c) merge.

optimum phase angles of $\varnothing=135^{\circ}$ and $\varnothing=315^{\circ}$, respectively. It was observed for each of the different eccentricity ratios studies. The critical adding mass ratios can also be predicted through its linear relationship with the eccentricity ratios. The diagrams are presented (Figures 17, 18, and 19) to show the effect of the MBM modelling balancing method. The results showed that the MBM method could reduce the vibration near the first critical speed sharply while keeping the vibration at working speed at a proper level, so the nonlinear constraint was an effective way to make the balancing machinery run up safely. As a result, MBM can reduce the vibration more effectively. The purpose of the modified MBM described in this paper is to solve realworld engineering problems. Using the limited (FRF) data engineers obtains the equivalent substructure model while avoiding tedious FE modelling processes. By associating the method with other applications, it can have a wide range of practical advantages, such as developing the online diagnostics of rotor system by improving its computer simulation efficiency.

The simulation values obtained from the ANSYS (Figure 20) are very similar to the experimental results (Figures 17, 18, and 19), in comparison with ANSYS (Figure 20(c)).

We find the relation between the bending stress with respect to time (Figures 21(a), 21(b)). As the performance of bending stresses at one disc in the middle when added 8 gram mass in the disc, the bending stress decreases in both directions of motion $(Y, Z)$ that means reducing the reaction force in the bearing to make the bearing long save life.

In this paper a simple mathematical model has been used, however, more elaborate models based on a much larger degree of freedom may be used, based on suppleness 


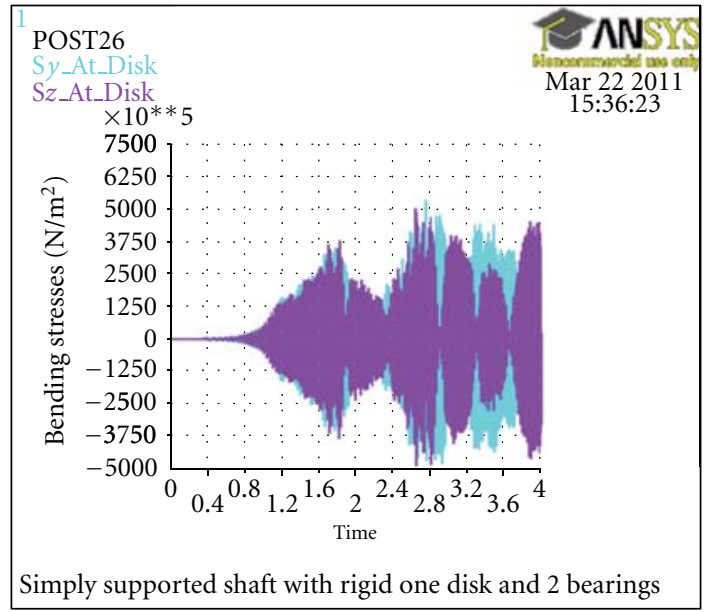

(a) Before add mass

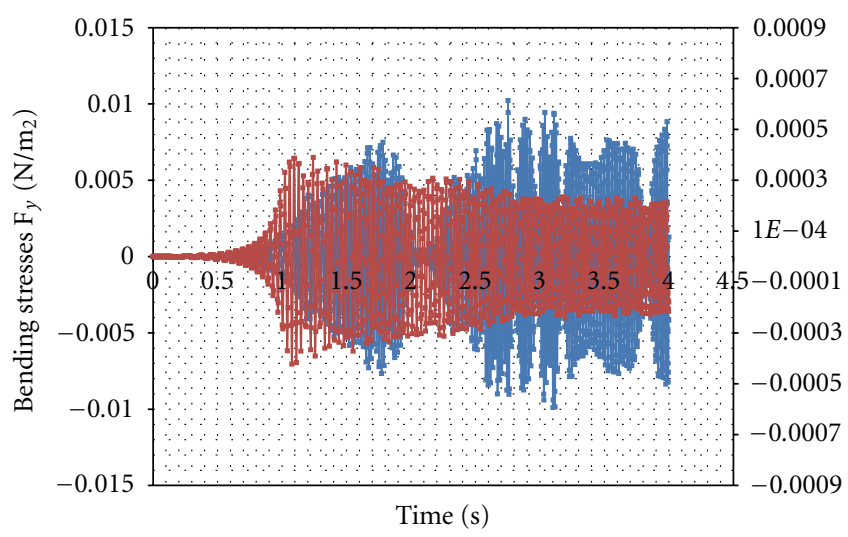

$\because$ Without load

(c) Merge in $Y$ direction

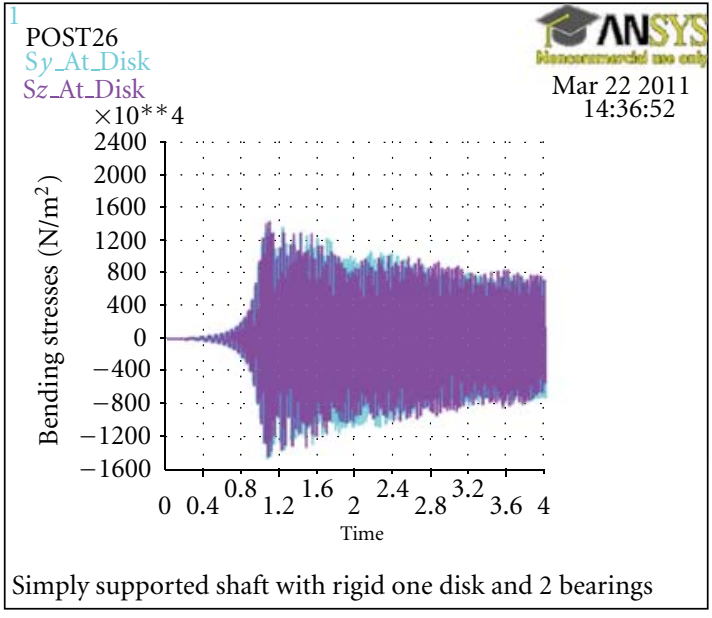

(b) After add 8 gram mass

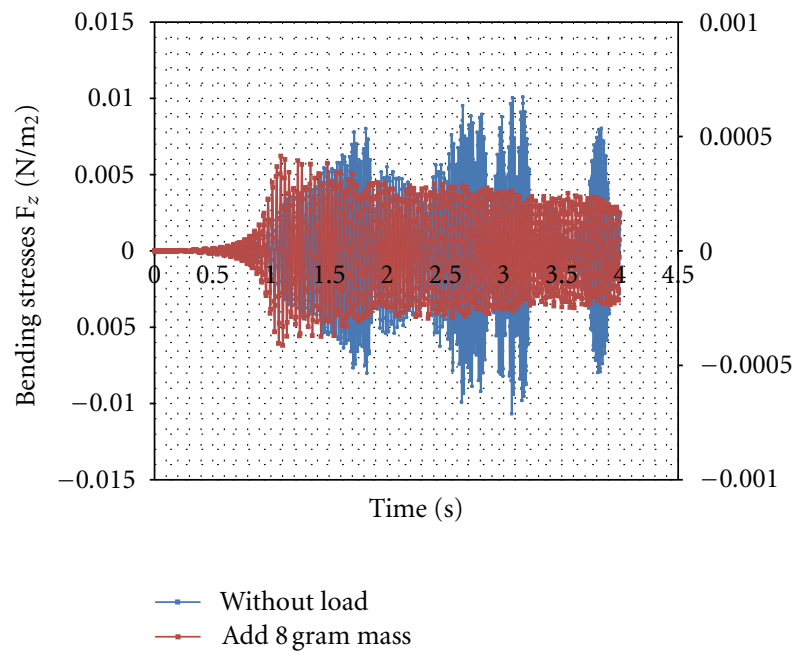

(d) Merge in $Z$ direction

FIGURE 21: Relation between the bending stress with respect time (second).

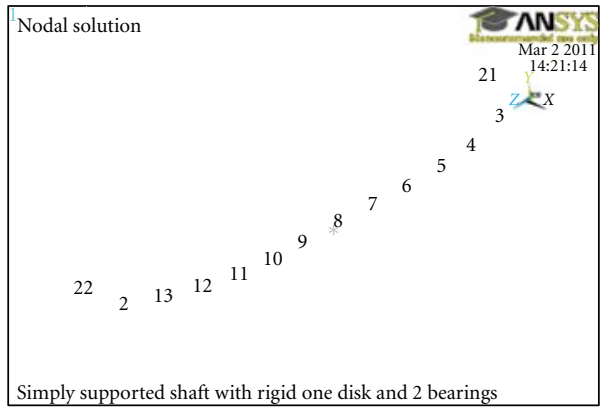

FIGURE 22: A typical operating deflection shape (ODS), ANSYS.

or stiffness influence coefficients. The mathematical models may also be used to refine the measured data and help in removal of contaminated data. It is, therefore, feasible to create a mathematical model as a database for various systems for condition monitoring during their life time of the machines.

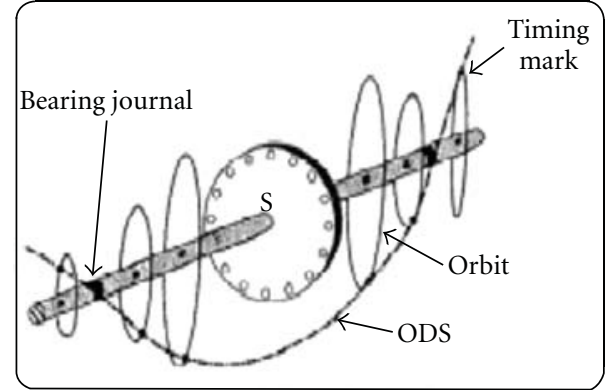

FIGURE 23: A typical operating deflection shape (ODS) for Jeffcottrotor, scourtesy of [12].

As the rotor spin speed increases, this offset will cause point $S$ to move outward relative to the bearing centreline (axis B), Figure 23, thereby producing a forced whirling motion. Forced whirling is a dynamic response motion with a 


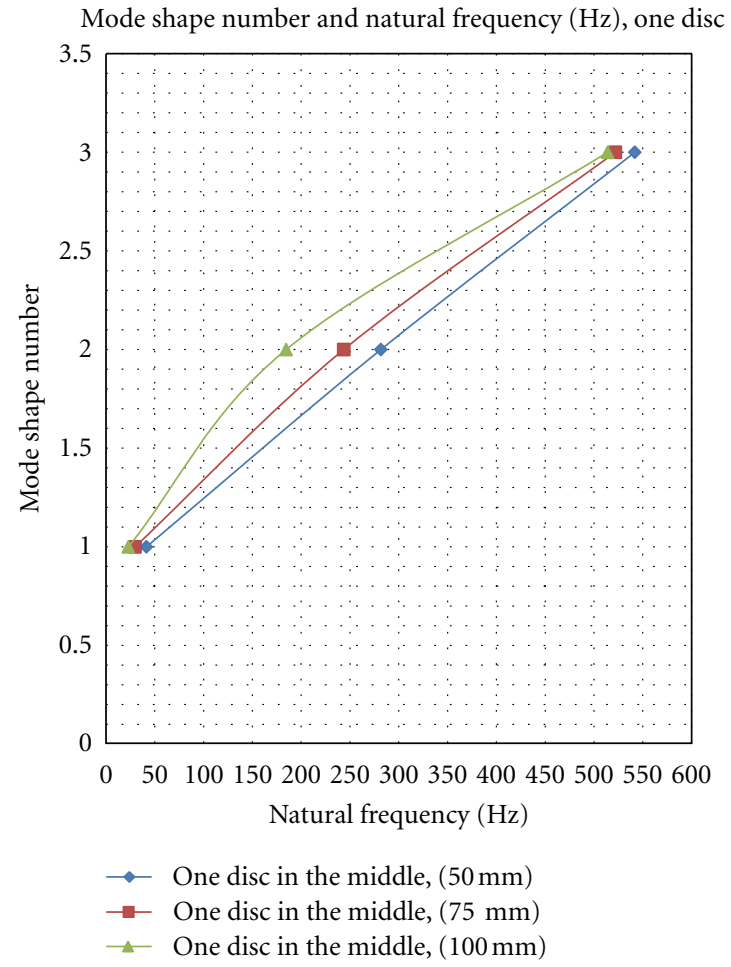

(a) One disc in the middle

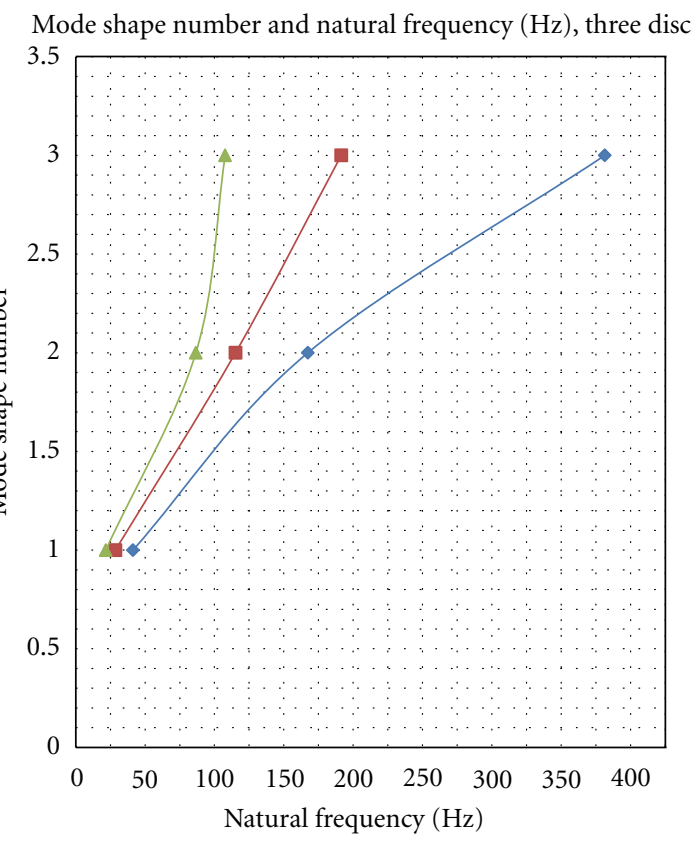

$\rightarrow$ Three discs with bearing, $(50 \mathrm{~mm})$

$\rightarrow-$ Three discs with bearing, $(75 \mathrm{~mm})$

$\triangle$ Three discs with bearing, $(100 \mathrm{~mm})$

(c) Three discs

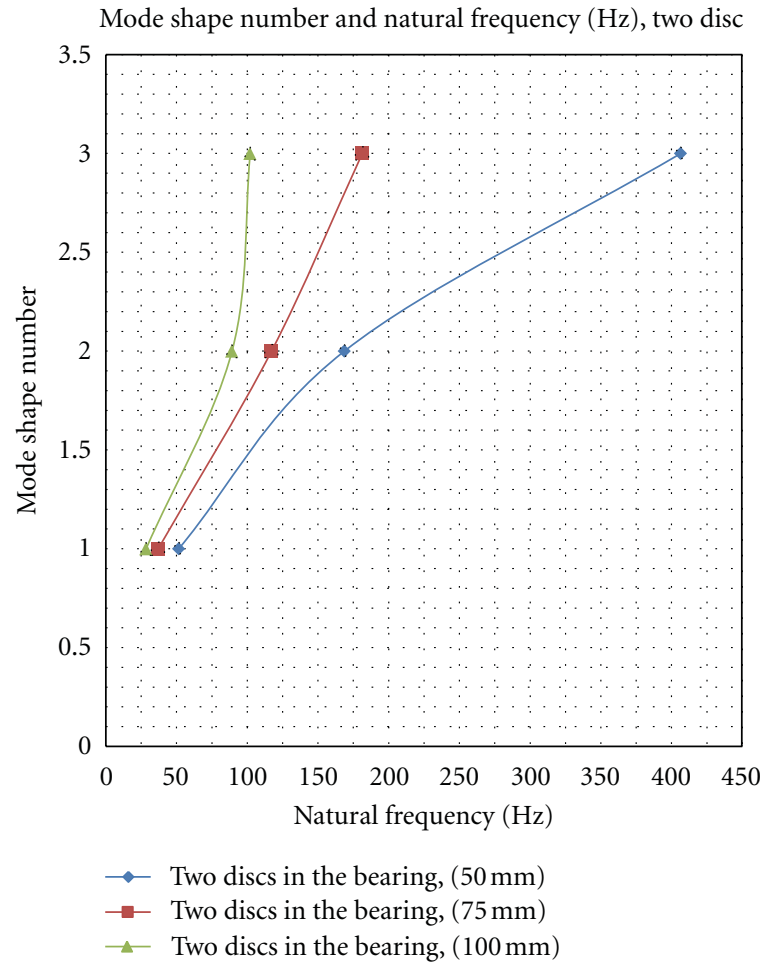

(b) Two discs in the effective length

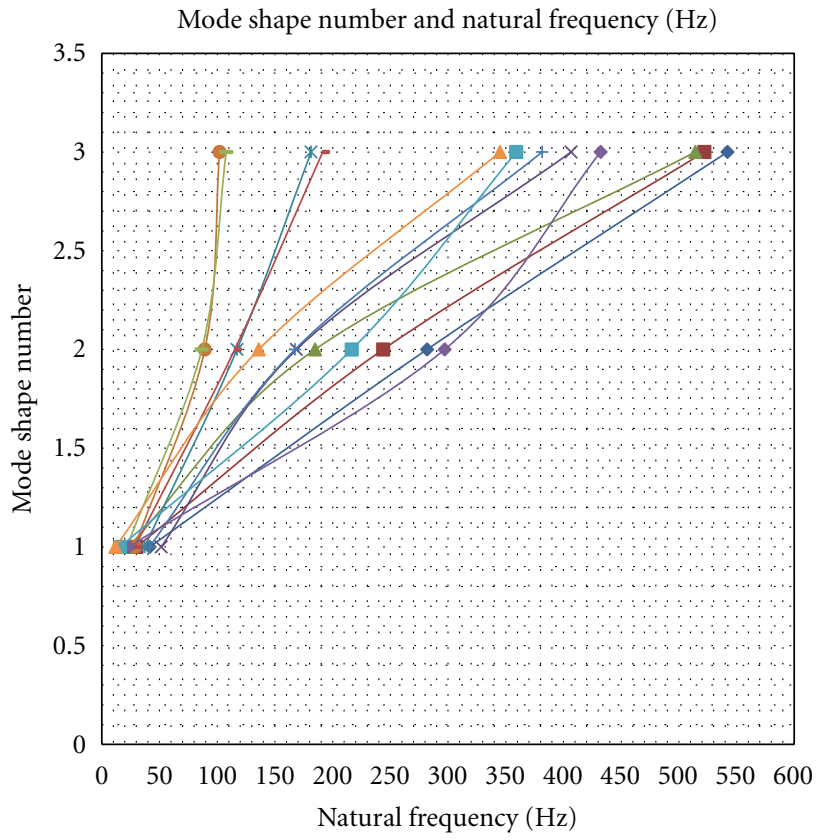

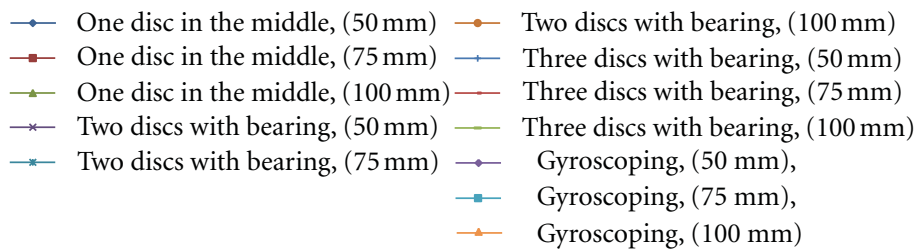

(d) Merge all cases

FIGURE 24: Relation between mode shape number versus natural frequency with different disc mass. 
definite shape, called the operating deflection shape (ODS); a typical example is shown in ANSYS Figure 22. It is important that the natural whirling modes not be confused with the ODS. Although different in concept, they are related. For each spin speed, a set of weighting factors can be found such that the weighted sum of the normalized natural whirling modes is equal to the ODS. This is known as the rotordynamic expansion theorem. In this review, we shall be concerned mainly with an ODS for which the whirling rate is equal to the spin speed, a condition known as synchronous whirling. Synchronous whirling is caused by unbalance (imbalance) and plots as a straight line of positive slope in $w$, $\Omega$ coordinates. It is also referred to as the one-time spin speed line, and labelled $1 \mathrm{X}$ has good agreement with Figure 23 [12].

With further simulation, we find the relation between mode shape number versus natural frequency $(\mathrm{Hz})$. We can see from Figures 24(a), 24(b), 24(c), and 24(d) the effect of change diameter of disc (change mass) to the natural frequency on (one, two, and three discs).

\section{Nomenclature}

$M, C, K: \quad$ Mass, damping, and stiffness matrices

$x, f: \quad$ Displacement, external force vectors

$U: \quad$ Mode shape matrix

$N$ : $\quad$ Total number of components

$\eta_{r}, v_{r}$ : Components of the modal coordinate and the mode shape vector at the $r$ th mode

$M$, $\varnothing$ and $K$ : Diagonal mass, damping, and stiffness matrices

$\varphi_{j r}$ the $j$ th: Components of the $r$ th mode shape vector

$\mu$ : $\quad$ Modal force vector

$f_{j}=\hat{f}_{j} e^{i \omega t}:$ Exciting forc

$x=\hat{x} e^{i \omega t}: \quad$ Displacement vector of the spatial model

$\omega: \quad$ Excitation frequency

$\omega_{r}: \quad$ Natural frequency of the $r$ th mode (modal parameters)

$\zeta_{r}: \quad$ Damping ratio of the $r$ th mode(modal parameters)

(FRF) $H_{i j}$ : Ratio of the $i$ th displacement component $\hat{x}_{\mathrm{i}}$ to the $j$ th exciting force component $\hat{f}_{j}$

$H_{i j, r}$ : $\quad$ Peak value of FRF at the $r$ th mode

$Y, Z$ : $\quad$ Directions at each of the bearing supports

\{\}$,[]: \quad$ Vector, matrix

${ }^{T}$ : $\quad$ Matrix transposition

FFT: $\quad$ Fast Fourier transform

FRF: $\quad$ Frequency response functions

DOFs: $\quad$ Degree of freedom system

ODS: $\quad$ Operating Deflection Shape

j: $\quad$ Unit imaginary.

\section{Acknowledgments}

The authors are deeply appreciative to the support derived from the Kingston University London and the Iraqi Ministry of Higher Education, Iraqi Cultural Attaché in London for supporting this research.

\section{References}

[1] H. Jimin and F. Zhi-Fang, Modal Analysis, Active, Butterworth Heinemann, Oxford, UK, 2001.

[2] L. Michel and F. Guy, Rotordynamics Prediction in Engineering, John Wiley \& Sons, Chichester, UK, 2nd edition, 1998.

[3] S. S. Rao, Mechanical Vibrations, Prentice Hall, Singapore, 2nd edition, 2005.

[4] J. Chaudhry, M. Wagner, F. He et al., "A complete rotordynamic analysis of a rotor-disc system using finite element method," in Proceedings of the 8th IFToMM International Conference on Rotordynamics, Seoul, Korea, September 2010.

[5] H. Irretier, "History and development of frequency domain methods in experimental modal analysis," Journal De Physique, vol. 12, no. 11, pp. 91-100, 2002.

[6] I. Bucher and D. J. Ewins, "Modal analysis and testing of rotating structures," Philosophical Transactions of the Royal Society A, vol. 359, no. 1778, pp. 61-96, 2001.

[7] H. Irretier, "Mathematical foundations of experimental modal analysis in rotor dynamics," Mechanical Systems and Signal Processing, vol. 13, no. 2, pp. 183-191, 1999.

[8] P. Pennacchi, N. Bachschmid, A. Vania, G. A. Zanetta, and L. Gregori, "Use of modal representation for the supporting structure in model-based fault identification of large rotating machinery: part 1-theoretical remarks," Mechanical Systems and Signal Processing, vol. 20, no. 3, pp. 662-681, 2006.

[9] D. J. Ewins, Modal Testing:Theory and Practice, John Wiley \& Sons, Exeter, UK, 1995.

[10] http://www.mpihome.com/.

[11] ANSYS 12 Help Menu (can be found with ANSYS 12).

[12] R. C. Eisenmann and R. C. Eisenmann Jr., Machinery Malfunction, Diagnosis, and Correction, Prentice Hall, 1998.

[13] G. T. Rocklin, J. Crowley, and H. Vold, "A Comparison of H1, $\mathrm{H} 2$, and HV frequency response Functions," in Proceedings of the 3rd International Modal Analysis Conference, pp. 272-278, Orlando, Fla, USA, 1985.

[14] M + P International, SO Analyser operating Manual.

[15] P. Reynolds and A. Pavic, "Structural testing series: part 7. Impulse hammer versus shaker excitation for the modal testing of building floors," Experimental Techniques, vol. 24, no. 3, pp. 39-44, 2000.

[16] H. D. Nelson and J. M. Mc Vaugh, "The dynamics of rotorbearing systems using finite elements," Journal of Engineering For Industry, vol. 98, no. 2, pp. 593-600, 1976.

[17] Y. D. Joh and C. W. Lee, "Excitation methods and modal parameter identification in complex modal testing of rotating machinery," Modal Analysis, vol. 8, no. 3, pp. 179-203, 1993.

[18] A. Beley, C. Rajakumar, and P. Thieffry, Computational Methods for Rotordynamics Simulation, NAFEMS World Congress, Crete, Greece, June 2009.

[19] J. H. Ginsberg, Mechanical and Structural Vibration, Theory And Applications, John Wiley \& Sons, New York, NY, USA, 2001.

[20] D. L. Formenti and M. H. Richardson, "Global curve fitting of frequency response measurements using the rational," in Proceedings of the 3rd International Modal Analysis Conference, pp. 390-397, Orlando, Fla, USA, 1985. 

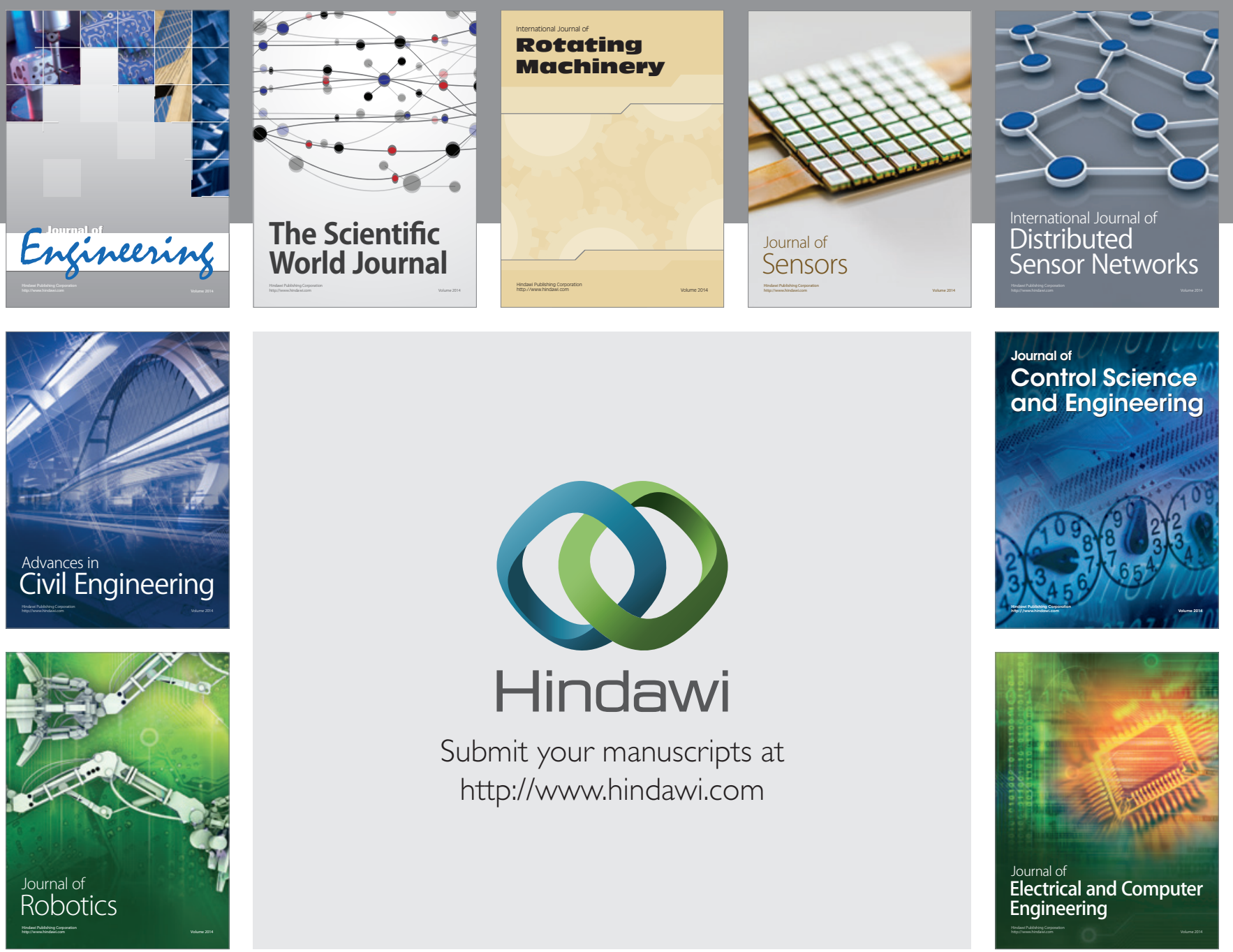

Submit your manuscripts at

http://www.hindawi.com
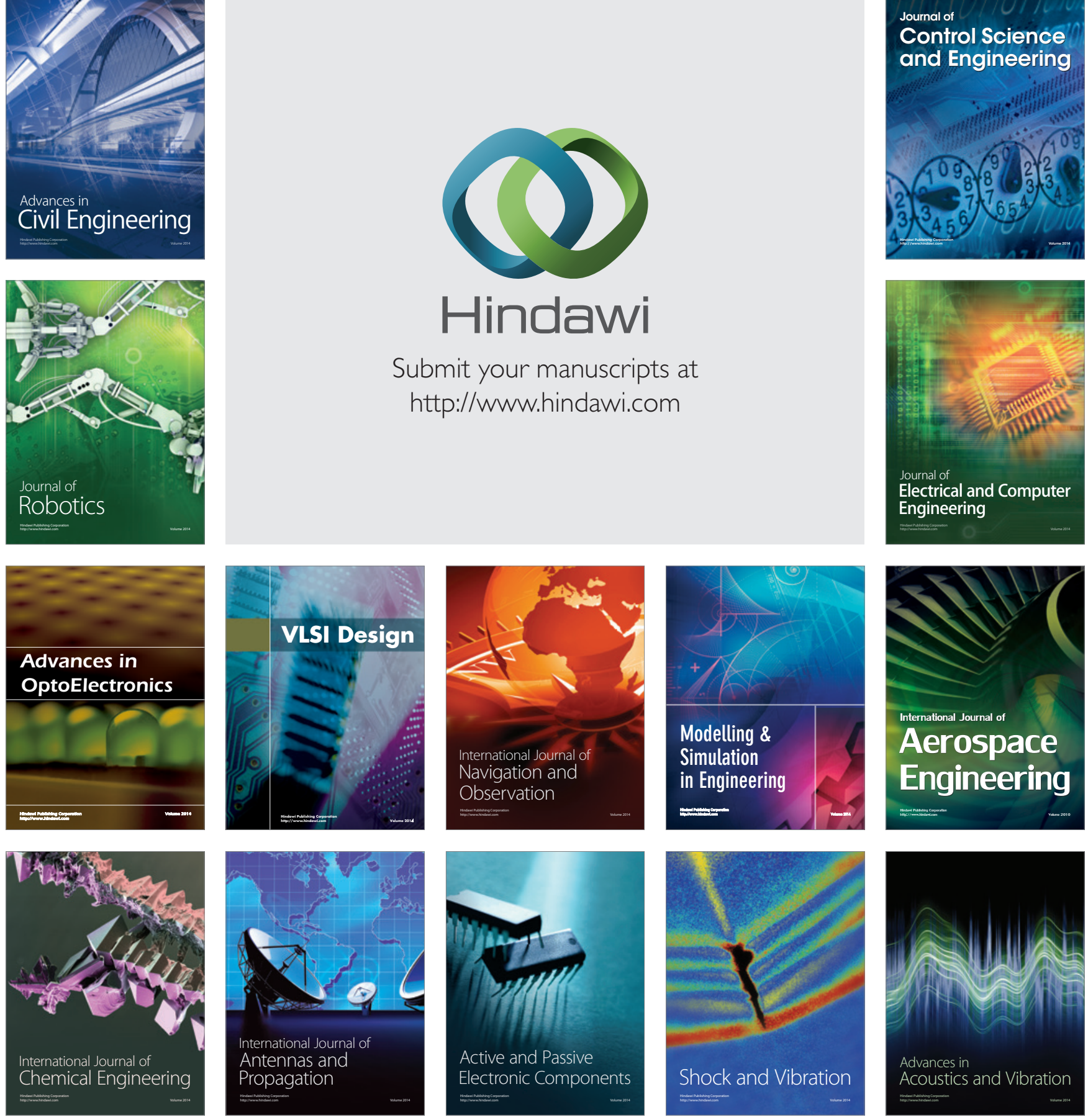